\title{
Article
}

\section{Match running performance in young soccer players: a systematic review}

\author{
Vieira, Luiz Henrique Palucci, Carling, Christopher, Barbieri, Fabio \\ Augusto, Aquino, Rodrigo and Santiago, Paulo Roberto Pereira \\ Available at http://clok.uclan.ac.uk/24825/ \\ Vieira, Luiz Henrique Palucci, Carling, Christopher ORCID: 0000-0002-7456- \\ 3493, Barbieri, Fabio Augusto, Aquino, Rodrigo and Santiago, Paulo Roberto \\ Pereira (2019) Match running performance in young soccer players: a \\ systematic review. Sports Medicine, 49 (2). pp. 289-318. ISSN 0112-1642
}

It is advisable to refer to the publisher's version if you intend to cite from the work. http://dx.doi.org/10.1007/s40279-018-01048-8

For more information about UCLan's research in this area go to http://www.uclan.ac.uk/researchgroups/ and search for <name of research Group>.

For information about Research generally at UCLan please go to http://www.uclan.ac.uk/research/

All outputs in CLoK are protected by Intellectual Property Rights law, including Copyright law. Copyright, IPR and Moral Rights for the works on this site are retained by the individual authors and/or other copyright owners. Terms and conditions for use of this material are defined in the policies page.

\section{CLoK}

Central Lancashire online Knowledge www.clok.uclan.ac.uk

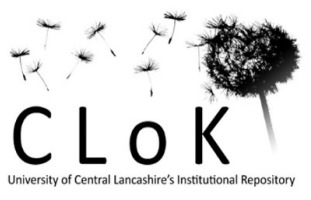




\title{
Match Running Performance in Young Soccer Players: A Systematic Review
}

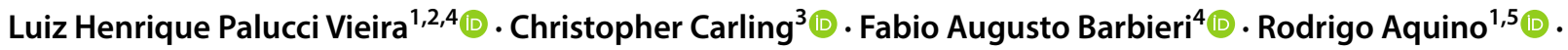 \\ Paulo Roberto Pereira Santiago ${ }^{1,2} \mathbb{E}$
}

(c) Springer Nature Switzerland AG 2019

\begin{abstract}
Background To date, athletic performance has been extensively assessed in youth soccer players through laboratory and field testing. Only recently has running performance via time-motion analysis been assessed during match play. Match running data are often useful in a practical context to aid game understanding and decision making regarding training content and prescriptions. A plethora of previous reviews have collated and appraised the literature on time-motion analysis in professional senior players, but none have solely examined youth players.

Objective The aim of the present systematic review was to provide a critical appraisal and summary of the original research articles that have evaluated match running performance in young male soccer players.

Methods Following the Preferred Reporting Items for Systematic Reviews and Meta-analyses (PRISMA) statement, literature searches were performed in four databases: PubMed, ISI Web of Science, SPORTDiscus and SciELO. We used the following descriptors: soccer, football, young, youth, junior, physical performance, running performance, match running performance, movement patterns, time-motion analysis, distances covered, activity profile, work rate, match analysis, and match performance. Articles were included only if they were original articles written in the English language, studied populations of male children and/or adolescents (aged $\leq 20$ years), were published/ahead of print on or before 31 December 2017 and showed at least one outcome measure regarding match running performance, such as total distance covered, peak game speed or indicators of activities performed at established speed thresholds.

Results A total of 5801 records were found. After duplicates were removed and exclusion and inclusion criteria applied, 50 articles were included ( $n=2615$ participants). Their outcome measures were extracted and findings were synthesized. The majority of the reviewed papers covered the European continent (62\%) and used global positioning systems (GPS) (64\%). Measurement error of the tools used to obtain position data and running metrics was systematically overlooked among the studies. The main aims of studies were to examine differences across playing positions (20\%), age groups (26\%) and match halves (36\%). Consistent findings pointed to the existence of positional role and age effects on match running output (using fixed running speed thresholds), but there was no clear consensus about reductions in activity over the course of match play. Congested schedules negatively affected players' running performance. While over $32 \%$ of all studies assessed the relationships between match running performance and physical capacity, biochemical markers and body composition, $70 \%$ of these did not account for playing position.

Conclusions This review collated scientific evidence that can aid soccer conditioning professionals in understanding external match loads across youth categories. Coaches working with youth development programs should consider that data derived from a given population may not be relevant for other populations, since game rules, match format and configuration are essentially unstandardized among studies for age-matched players. Despite limited evidence, periodization training emphasizing technical-tactical content can improve match running performance. Occurrence of acute and residual impairments in the running performance of young soccer players is common. Prescription of postmatch recovery strategies, such as cold water immersion and spa treatment, can potentially help reduce these declines, although additional research is warranted. This review also highlighted areas requiring further investigation, such as the possible influence of environmental and contextual constraints and a more integrative approach combining tactical and technical data.
\end{abstract}

Extended author information available on the last page of the article 


\section{Key Points}

The number of studies on match running performance has exponentially increased over the current decade in youth soccer populations, providing information that could aid the development of physical conditioning programs and their prescription across different age categories.

While the current empirical evidence provides a general understanding of external match loads across different age groups, disparities in experimental approaches across studies in age-matched players exist, whilst measurement error and the potential impact of situational variables are also frequently overlooked.

Match running activity can decrease over the course of games and during fixture congestion (i.e., signs of acute and residual fatigue, respectively), yet information is limited on the effects of recovery interventions (e.g., cold water immersion and spa treatment) to temper performance declines during intensive schedules.

\section{Introduction}

Professional soccer clubs invest significant amounts of money to nurture elite players $[1,2]$. The monitoring of match running performance using time-motion analysis (TMA) is now considered a fundamental part of contemporary youth development processes [3]. This is reflected by a notable shift in the body of knowledge over the current decade compared with 10 years ago, when a review showed a lack of information on match play running performance in youth soccer players [4]. While several further reviews have collated and appraised the TMA literature, none have solely examined younger populations (e.g., Mohr et al. [5], Sarmento and colleagues [6, 10], Lago-Peñas [7], Carling et al. [8], Reilly et al. [9], Taylor et al. [11]) despite a plethora of original investigations comparing performance across different age groups [12-20].

In general, running data are useful in a practical context to aid game understanding and decision making in relation to individual and collective physical training content and prescriptions [4, 21-24]. This information can also help distinguish player performances across different competitive standards [6] and improve understanding of the potential effects of contextual factors such as match location, quality of opponents, and match status [25]. Regarding youth players, TMA data can also help to clarify the demands necessary when moving up into older age brackets, especially when talented youth players (e.g., U18-U20) are promoted to the senior squad. The data can help determine at which age(s) young players demonstrate match running outputs that are sufficient to meet the demands of professional standards. Insights into athletic and game evolution can be gained that, in turn, enable the tailoring of age-specific training programs [3] and improvement of long-term training interventions [18] and help avoid replication of methods used in senior players, since very young soccer players should not be considered small adults [24, 26].

Yet, to our knowledge, critical appraisals of study design and the information derived from TMA of match running performance at the youth level are currently lacking [3]. For example, it is necessary to investigate the potential discrepancies among studies in the cutoffs used for age-band definitions (12 months [14, 15, 18] or 24 months [20, 27, 28]) and running speed thresholds (e.g., high-intensity running: 13.1-16 [18], 15.1-18 [29], 15-36 [30], and $>19.8 \mathrm{~km} / \mathrm{h}$ [31]) for age-matched players. Furthermore, in contrast with senior players $[3,7,20]$, the potential impact of contextual factors, also known as situational variables (e.g., influence of match location or result), has not been examined in younger players. Finally, investigations of the possible effects of match format (e.g., small-sided games [13, 32] or full-sized pitches $[16,18,24])$ and decrements in performance (e.g., half-times $[3,16,17]$ and specific game periods $[13,15,33])$ would be beneficial to aid in the understanding of the characteristics specific to youth soccer match play. Therefore, the purpose of the present systematic review was to provide a critical appraisal and summary of original research articles that have investigated match running performance in young male soccer players.

\section{Methods}

\subsection{Search Strategy}

This systematic review was conducted according to the Preferred Reporting Items for Systematic Reviews and MetaAnalyses (PRISMA) statement [34]. Permission was granted by the Institutional Human Research Ethics Committee (School of Physical Education and Sport of Ribeirão Preto, University of São Paulo, Brazil; protocol number CAAE 61884716.9.0000.5659). The searches for relevant content related to the running performance of young soccer players during match play were performed on 31 December 2017, using four electronic databases: PubMed/NCBI (National Center for Biotechnology Information, US National Library of Medicine), Institute for Scientific Information (ISI) Web of Knowledge, SciELO (Scientific Electronic Library Online), and SPORTDiscus via EBSCOhost. In each database, the following descriptors were used: [soccer OR 
football] AND [young OR youth OR junior] AND [physical performance OR running performance OR match running performance OR movement patterns OR time-motion analysis OR distances covered OR activity profile OR work rate OR match analysis OR match performance]. Additional searches were performed on Google Scholar when the full texts were not available in these databases and for articles found on ResearchGate ${ }^{\mathrm{TM}}$ [35]. Dedicated computer software (EndNote X7, Thomson Reuters ${ }^{\odot}$, New York, NY, USA) was used for reference management, facilitating deduplication and screening steps.

\subsection{Selection Criteria}

\subsubsection{Inclusion Criteria}

We opted to include papers if they filled all of the following criteria: (1) original article; (2) abstract available for screening; (3) samples of male children and/or adolescents; (4) published in the English language; (5) published/ahead of print up to and including 31 December 2017; (6) in a scientific indexed peer-reviewed scientific journal (thus, abstracts published in conference proceedings, books, theses, dissertations, reviews, systematic reviews, and meta-analyses were not considered); (7) included at least one outcome measure regarding the following dependent variables of match running performance: total distance covered, mean speed or distance covered per time, peak game speed, activities performed at established speed thresholds (e.g., expressed as distance covered, distance covered per minute, percentage of total distance covered) or movement category (e.g., subjective estimates of percentage of time in walking, jogging; low, medium, and high intensities). No restrictions regarding the date of publication were imposed, other than those described in item 5 .

\subsubsection{Exclusion Criteria}

Exclusion criteria included (1) goalkeepers as participants; (2) female participants; (3) samples presenting a mean age $>20$ years; (4) matches performed on pitches with reduced dimensions (i.e., small-sided games, except as defined by the local soccer governing body according to information presented in the text); (5) games played as training/practice sessions; (6) laboratory-based and/or field tests measuring running performance; (7) use of running protocols to simulate soccer match play demands; (8) studies investigating other football codes (American football, Australian Rules football, Gaelic football, rugby, indoor soccer) rather than soccer; (9) unrelated samples (e.g., referees); and (10) soccer players competing and/or originally described as senior professionals or semiprofessionals. We also excluded articles that did not contain one of the descriptors cited in the search strategy (see Sect. 2.1) in the title, abstract and/ or keywords.

\subsection{Methodological Quality Assessment}

The methodological quality was assessed in line with two previous review articles related to sport physical performance [35] and soccer match running data collection [36]. All of the included studies were appraised using the answers to nine questions (Q1-9), designed with minor adaptations from the aforementioned systematic review papers (Table 1). For this purpose, a three-point scale was adopted (where "yes" = 2 points; "maybe" $=1$ point; "no" $=0$ ), except for Q4 [36]. Strict rules that were applied to Q2, Q3 and Q8 are also described in a footnote to Table 1 . Next, a summation of the attributed points from all the questions was performed for each study; the possible quality rating varied from 0 to 18 points. Finally, the obtained values were converted into percentages (minimum 0\% to maximum 100\%). The studies were deemed to have an appropriate level of quality when they scored $>75 \%$ [35]. Methodological quality was not evaluated for the purpose of including/excluding studies.

\subsection{Data Extraction}

In each search in the aforementioned databases, two evaluators (LV, RA) independently examined the article title, abstract and keywords in the first stage of screening according to the established inclusion and exclusion criteria. Interrater agreement was evaluated by Cohen's kappa coefficient $(k)$. If any disagreements occurred, a senior researcher (CC) examined the situation on a case-by-case and determined the inclusion or exclusion of a given article using his greater experience in the field. The agreement rate was $k=0.97$. We examined the texts to identify the terminologies employed in reference to the method used and for running performance variable(s) definition. Demographic details of the included studies were then extracted, including sample size, age/ age group of the participants and the geographical location where the study was conducted. Methodological descriptions included match type, format (pitch size, number of players a-side, whether a rolling substitute policy was adopted) and configuration (duration and number of periods), measurement techniques/equipment, acquisition frequency used to obtain running performance data and speed threshold limits. Finally, general results regarding match running performance were extracted and the main findings were organized and described in Sect. 3.4. When outcome measures were presented as figures (e.g., column graphics), a specific routine that was custom written in the MATLAB ${ }^{\circledR}$ environment (The MathWorks Inc., Natick, USA) using the "ginput.m" function was employed to perform a more accurate extraction of the data. 
Table 1 Methodological quality assessment scoring system

\begin{tabular}{|c|c|c|c|}
\hline & Question & Answer & Score \\
\hline Q1 & Study objective(s) is/are clearly set out & Yes $=2 ;$ Maybe $=1 ;$ No $=0$ & $0-2$ \\
\hline Q2 & Demographic data are presented (including assignment of age/age group, maturity status measured) & Yes $=2 ;$ Maybe $=1 ; \mathrm{No}=0$ & $0-2$ \\
\hline Q3 & $\begin{array}{l}\text { Game rules (including five items: match duration, field size, players a-side, match type, whether roll- } \\
\text { ing substitute policy was adopted) are described }\end{array}$ & Yes $=2 ;$ Maybe $=1 ;$ No $=0$ & $0-2$ \\
\hline Q4 & $\begin{array}{l}\text { The reliability/validity of the time-motion system/equipment is not stated, mentioned (i.e., a citation } \\
\text { of previous studies) or measured under local conditions where data collections took place }\end{array}$ & $\begin{array}{l}\text { Measured }=2 ; \text { Mentioned } \\
\quad=1 ; \text { Not stated }=0\end{array}$ & $0-2$ \\
\hline Q5 & Dependent variables defined & Yes $=2 ;$ Maybe $=1 ;$ No $=0$ & $0-2$ \\
\hline Q6 & $\begin{array}{l}\text { The duration of players recordings/inclusion criteria (an entire half time, a whole match, a certain } \\
\text { percentage, etc.) is clearly indicated }\end{array}$ & Yes $=2 ;$ Maybe $=1 ;$ No $=0$ & $0-2$ \\
\hline Q7 & Statistics are appropriate & Yes $=2 ;$ Maybe $=1 ; \mathrm{No}=0$ & $0-2$ \\
\hline Q8 & $\begin{array}{l}\text { Results are detailed (mean and standard deviation, percent change/difference, effect size/mechanistic } \\
\text { magnitude-based inference) }\end{array}$ & Yes $=2 ;$ Maybe $=1 ;$ No $=0$ & $0-2$ \\
\hline Q9 & Conclusions are insightful (clear, practical applications, and future directions) & Yes $=2 ;$ Maybe $=1 ;$ No $=0$ & $0-2$ \\
\hline Total & & & $0-18$ \\
\hline
\end{tabular}

Adapted from Bishop et al. [35], Castellano et al. [36], with permission

Strict rules applied to Q2 (no information $=0$ point; only age/age group was informed $=1$ point; maturity offset also measured $=2$ points); Q3 $(0-1$ item described $=0$ point; $2-3$ items described $=1$ point; $4-5$ items described $=2$ points); and Q8 (description of mean, standard deviation and null hypothesis significance test [p-value] $=1$ point; also included effect size/magnitude-based inferences $=2$ points)

\section{Results}

\subsection{Search Results}

The search process obtained 5801 records. Figure 1 presents the number of articles found in each electronic database and a flow chart of the literature search, including all the steps performed. Following the removal of duplicates, 2102 titles remained in the reference manager. Following the examination of titles, abstracts and keywords of all these manuscripts, 73 academic studies were eligible and retained for additional (i.e., full-text) analysis; 34 articles were excluded at this stage. Upon further inspection of the full text of the eligible articles and their respective bibliographical references, a total of 50 articles [12-20, 23, 24, 26-33, 37-67] fulfilled all of the inclusion criteria and none of the exclusion criteria and were included in the current systematic review (i.e., qualitative analysis).

\subsection{Methodological Quality}

The methodological quality scores attributed to the included studies can be found in Table 2 . Scores for the articles ranged from a minimum of 44\% [66] to the maximal possible score $(100 \%)$ (two studies [20, 47]). We identified a mean \pm standard deviation quality score for the 50 selected articles of $79 \pm 13 \%$. Several papers $(N=20)$, accounting for $40 \%$ of the total literature, were classified as $80-90 \%$ [13, 14, 16, $17,19,24,26,29,30,33,38,41,42,48,49,52-54,57,60]$; in addition, six papers $(12 \%)$ received very high ratings of between 90 and $100 \%[15,18,20,46,47,51]$. A total of $72 \%$ of the papers $(N=36$ publications $[12-20,24,26,28-30,32$, $33,38,40-43,46-49,51-54,56-58,60-63])$ reached an appropriate quality score, being classified as $>75 \%$ [34], and this was not the case for the remaining articles $(28 \% ; N=14$ publications [23, 27, 31, 37, 39, 44, 45, 50, 55, 59, 64-67]).

\subsection{Research Paradigm}

\subsubsection{General Information}

Table 3 describes in detail the demographic and methodological characteristics of the included papers. Running performance was investigated in match play in a total of 2615 young players. This represents a mean of $\approx 52$ players per study. The sample sizes ranged from a minimum of six [37] to a maximum of 380 [48] participants. The earliest articles were published in 2001 [37, 59]. Figure 2 shows the yearly distribution frequency of publications since 2000 . A gradually increasing trend has occurred over the current decade (2010-2017; approximately five articles published per year) compared with the previous decade (2001-2009; approximately one article published per year). The mean age for the youngest group identified was 7.9 years [20], and the oldest group included 20-year-old players [57]. The majority of evaluations were from the European continent (62\% of the total): England (14\%) [13, 15, 19, 26, 33, 44, 47], Italy (10\%) [20, 24, 37, 57, 66], Denmark [38, 54, 67], Portugal [43, 62, 65], Poland [23, 55, 64], Spain [56, 61], San Marino [39, 40], Norway [31, 59], Turkey [29], Croatia [50] and Austria [49]. Other investigations were conducted in Asia, particularly in Qatar (18\%) [12, 14, 17, 18, 41, 42, 


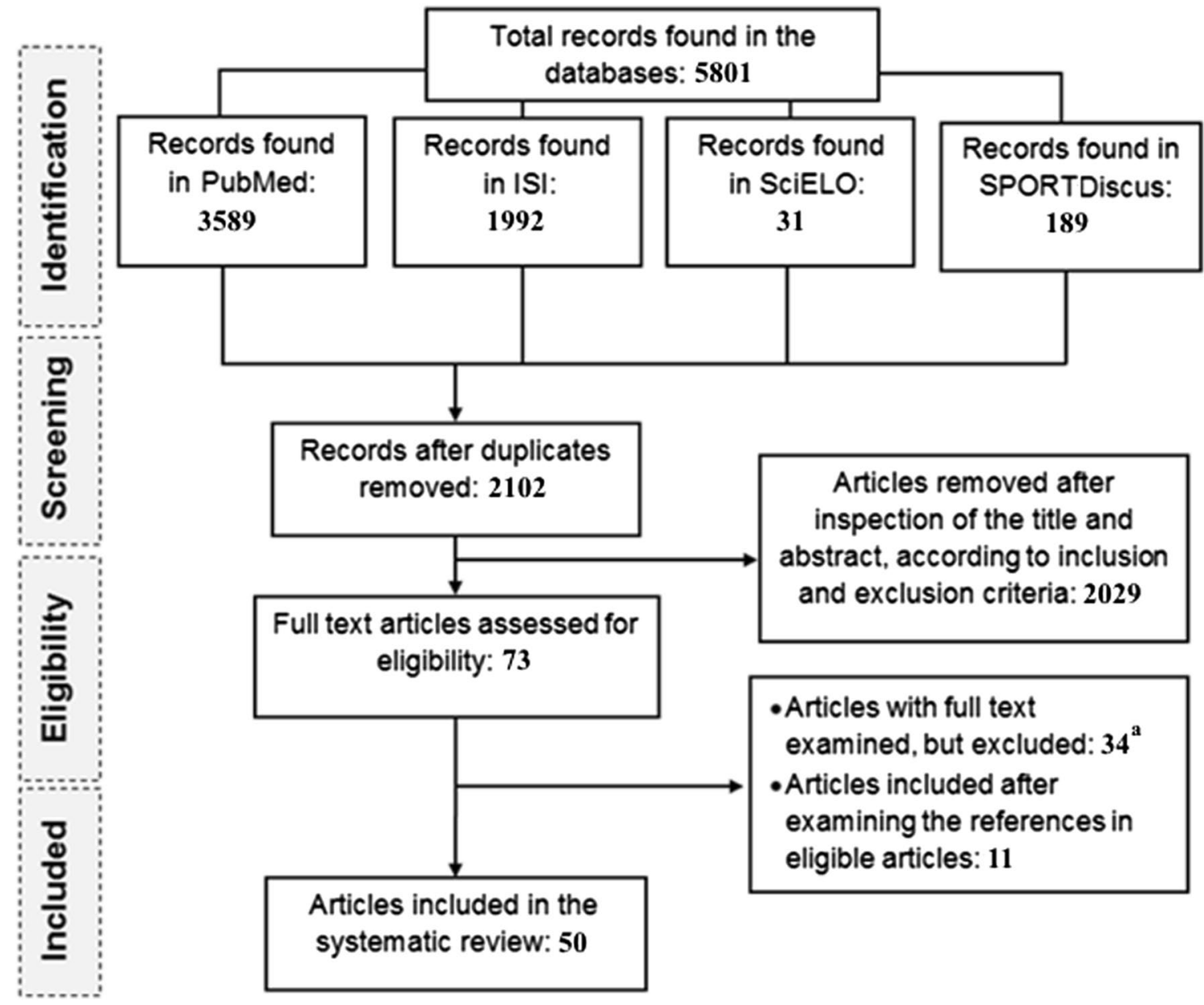

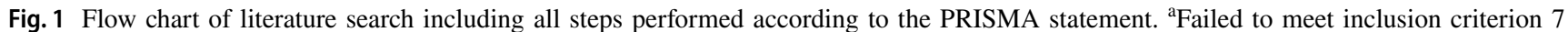
$(n=7)$, and fulfillment of exclusion criteria $3(n=3), 4(n=1), 5(n=3), 6(n=17)$ and $7(n=3)$

48, 51, 60]. Studies from Oceania (10\%), including New Zealand [15] and Australia [30, 52, 53, 58], were also identified. The remaining publications were from North America (USA [53]) and South America (14\%), most frequently Brazil $(10 \%)[27,28,32,45,46]$; two records from Bolivia [30, 58] were also found (Table 3).

\subsubsection{Study Objectives}

The main study objectives identified were primarily to characterize general game demands (22\%) [12, 14, 15, 23, 24, 26, $27,29,43,48,64]$ and to compare the running performance between playing positions (20\%) $[12,14,18,19,23,27,48$, $62,65,66]$, age groups (26\%) [12-18, 20, 26, 27, 60, 66, 67] and match halves/periods (36\%) [12, 14, 16, 20, 23, 24, 29, $31,32,37-40,45,48,56,57,64]$. Further studies also examined the influence of biological maturity $[38,51,60]$, playing standards $[33,38,48,54]$ and retained versus released players $[15,19,26]$ and compared match running performances between game formats $[37,54,61]$ and between specific training regimens [63]. Approximately one-third of all the studies evaluated relationships between the variables of match running performance and (1) anthropometric measures (e.g., height, body weight, and skinfolds) [50, 60], (2) physiological markers [45, 57] (e.g., creatine kinase [CK], lactate dehydrogenase [LDH], cortisol, interleukin [IL]-6, and testosterone levels) and, more frequently, (3) indicators of physical capacity provided through laboratory-based methods (e.g., maximal oxygen consumption $\left[\dot{V} \mathrm{O}_{2 \max }\right]$ and speed attained at $\dot{V} \mathrm{O}_{2 \max }\left[\mathrm{v} \dot{V} \mathrm{O}_{2 \max }\right]$ obtained through an incremental treadmill protocol) and field testing (e.g., YoYo Intermittent Recovery Test Level 1 (YoYo IR1) [68], running-based anaerobic sprint test (RAST) [69], Hoff test [70] and Vam-Eval test [71]) [14, 17, 18, 20, 28, 29, 39, 40, 43, 46, 47, 65]. Researchers also investigated the effects of match congestion [49, 51, 52], moderate [53] and high 


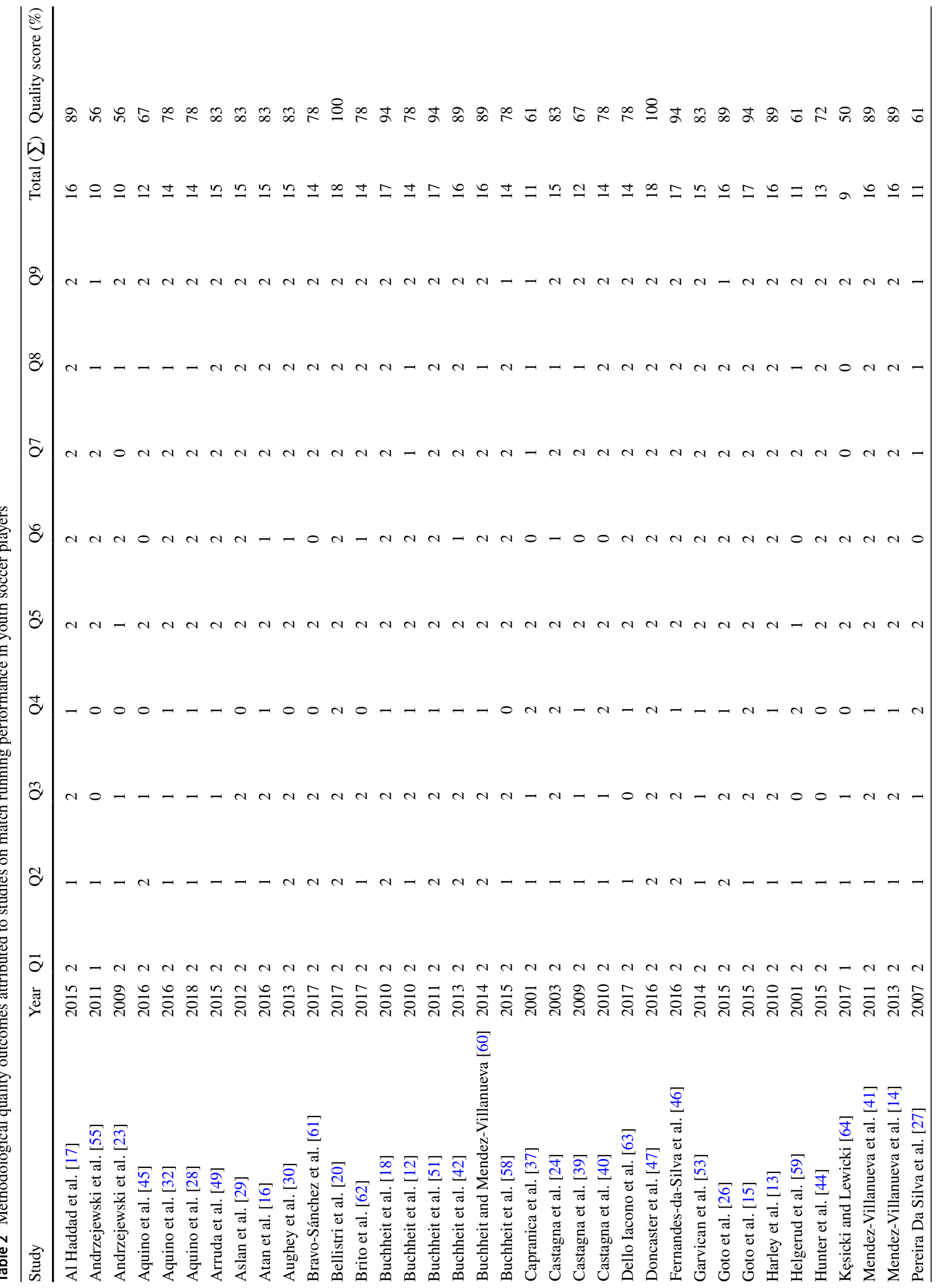




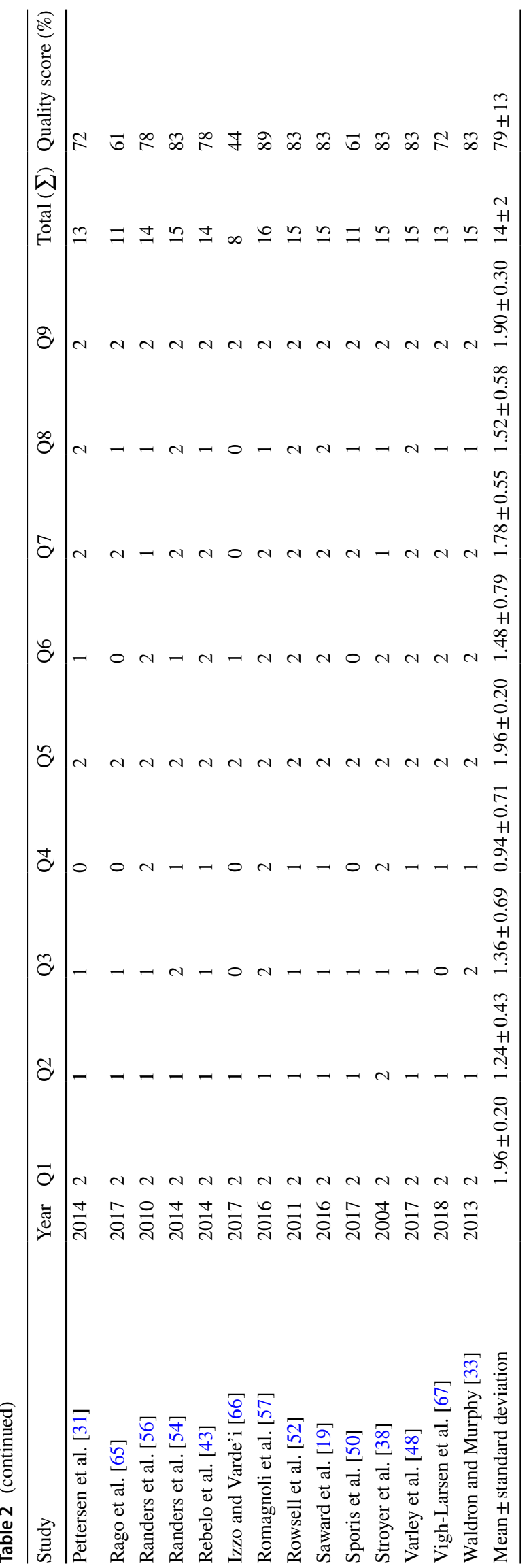

altitude [30, 58], specific pitch surface [62] and opponent quality [48] on running performance. Seasonal changes in physical capacity (i.e., performance derived from fitness tests) associated with those in match running performance were examined [42]. Also examined were interventional preand postmatch strategies, including prematch supplementation with caffeine [31] and postmatch recovery using cold water immersion [52] or spa treatments (combined sauna, cold water immersion and jacuzzi) [51]. Five remaining articles (10\% of the total) investigated the effects of training on running performance during match play using longitudinal experimental approaches [19, 32, 42, 55, 59]. Figure 3 presents the various research topics addressed in the studies on match running performance.

\subsubsection{Match Type and Configuration}

In total, 29 studies (58\% of the total) analyzed performance in official competitions [13-20, 23, 24, 26-28, 33, 37-40, $43,44,48-51,61,63,65-67]$, eight (16\%) were friendly matches $[12,29,30,41,42,53,58,60]$ and $11(20 \%)$ were simulated matches $[31,32,45-47,52,54,56,57,62,64]$. Two studies did not clearly specify the match type [55, 59]. Among the studies, 50\% exclusively used a game format with 11 players a-side $[12-17,24,27,29,30,37,39-43$, $46,47,50,51,54,57,60,62,65]$. Some of these compared age groups and used the 11-a-side format regardless of age (e.g., U11 to U16 [15], U12 to U16 [13] and U13 to U18 [12, 14, 42, 51]). In contrast, Goto et al. [26] employed 6 versus 6 in the U9-U10 age groups, and Bellistri et al. [20] used 5 versus 5 and 7 versus 7 for U8 and U10 players, respectively. Additionally, Saward et al. [19] examined U9 to U18 soccer players, adopting 11 versus 11 in U12 to U18s, whereas the authors adjusted the number of players per side for the younger players of U9-U10 (5 vs. 5 and 7 vs. 7) and U11s (7 vs. 7 and 11 vs. 11). The remaining articles (44\%) did not provide sufficient information to fully characterize the number of players per side $[23,28,31,32,38,44,45,48$, $49,52,53,55,56,59,63,64,66,67]$. Some studies (8\%) (England [13, 33], Italy [20], New Zealand [16]) adopted a rolling substitute policy, in which players were allowed to return to the field after being replaced. One study [53] used both the official and the interchangeable substitution methods. Additional information regarding game configuration (field size, duration and number of playing periods) is presented in Table 3.

\subsubsection{Speed Thresholds}

Table 4 presents speed thresholds adopted (i.e., superior and inferior speed limits) across studies. A total of 34 studies employed arbitrary fixed speed thresholds $(68 \%$ of the total) with unit measures in $\mathrm{km} / \mathrm{h}$ or $\mathrm{m} / \mathrm{s}[12,15$, 


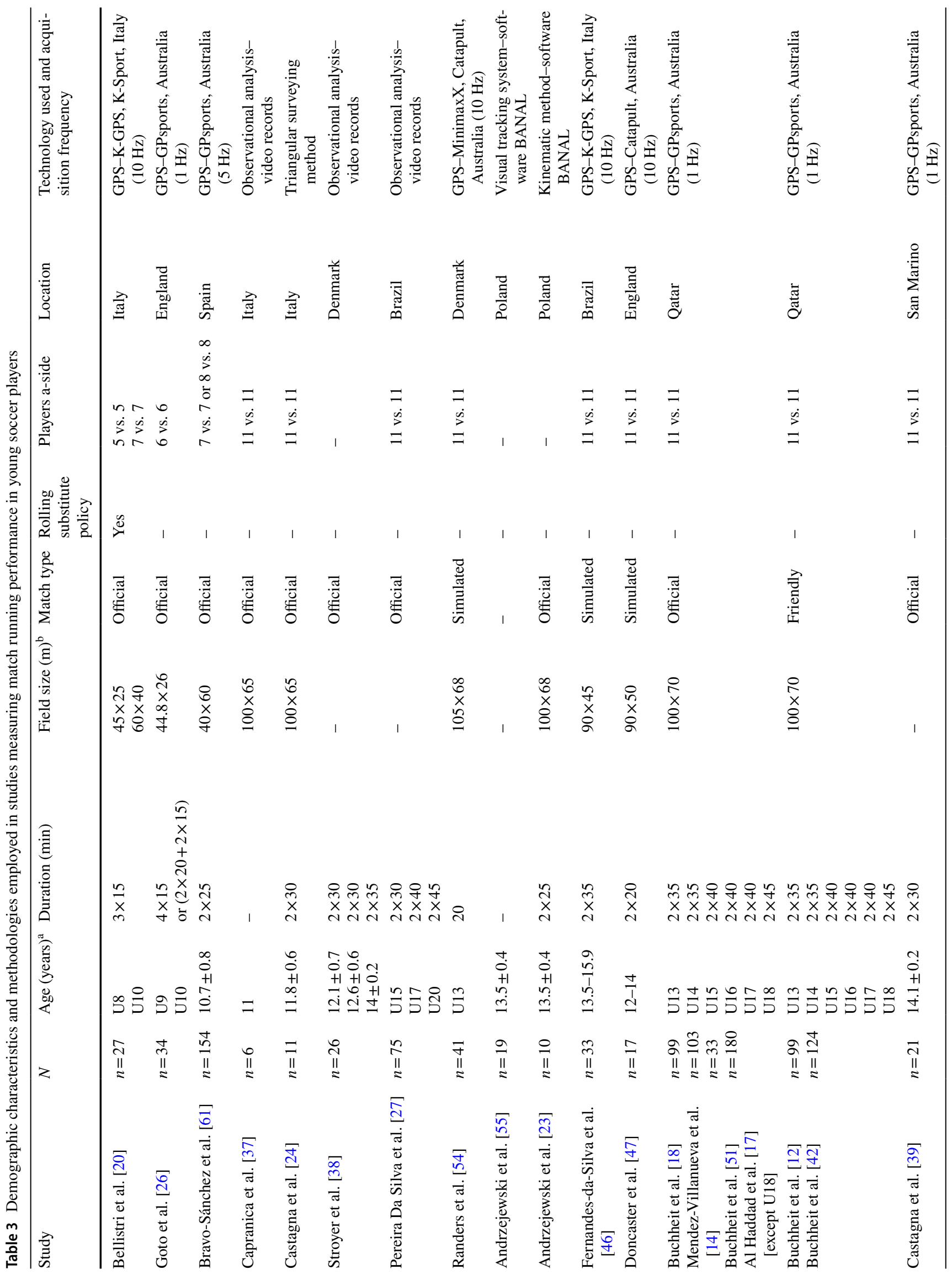




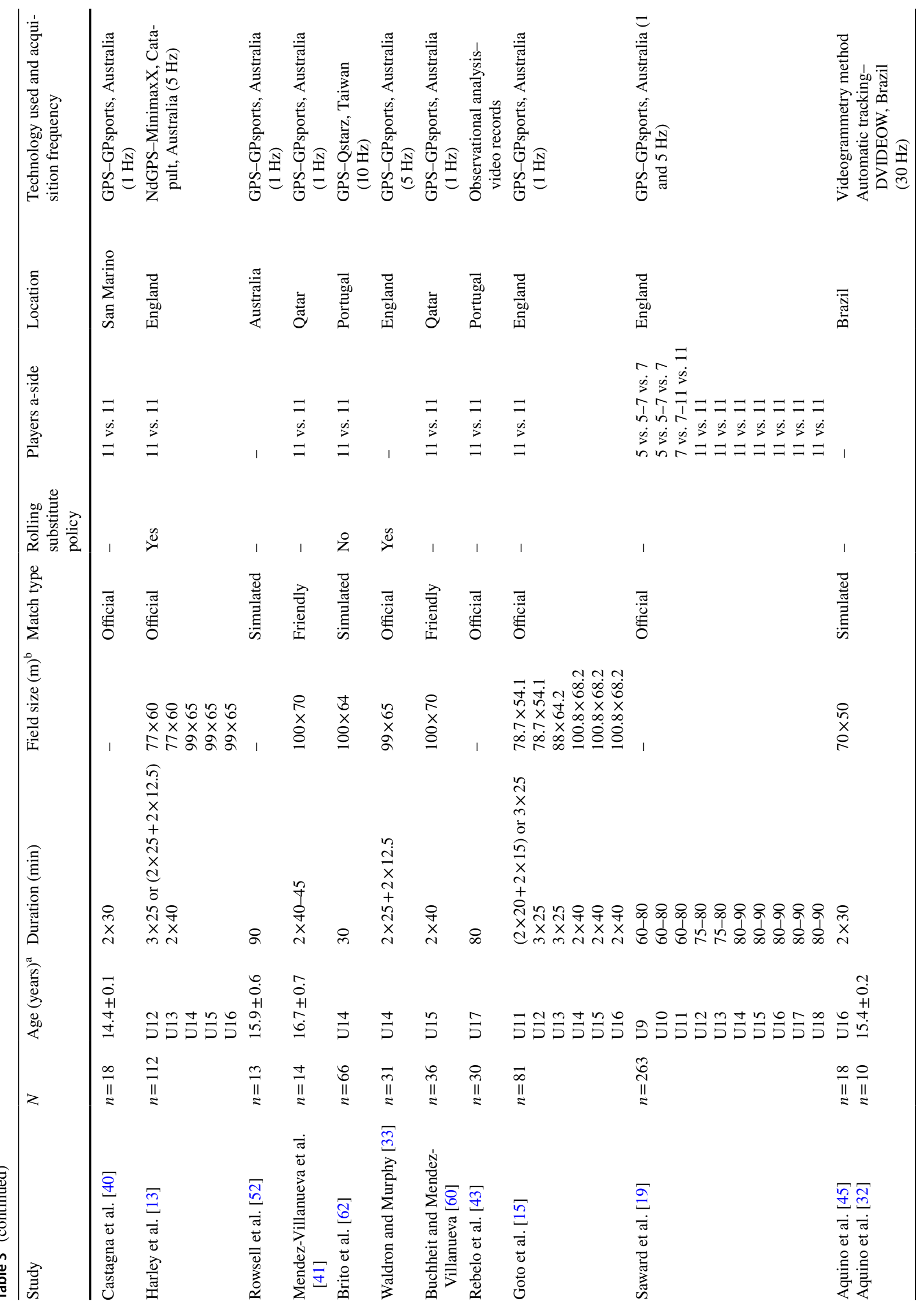




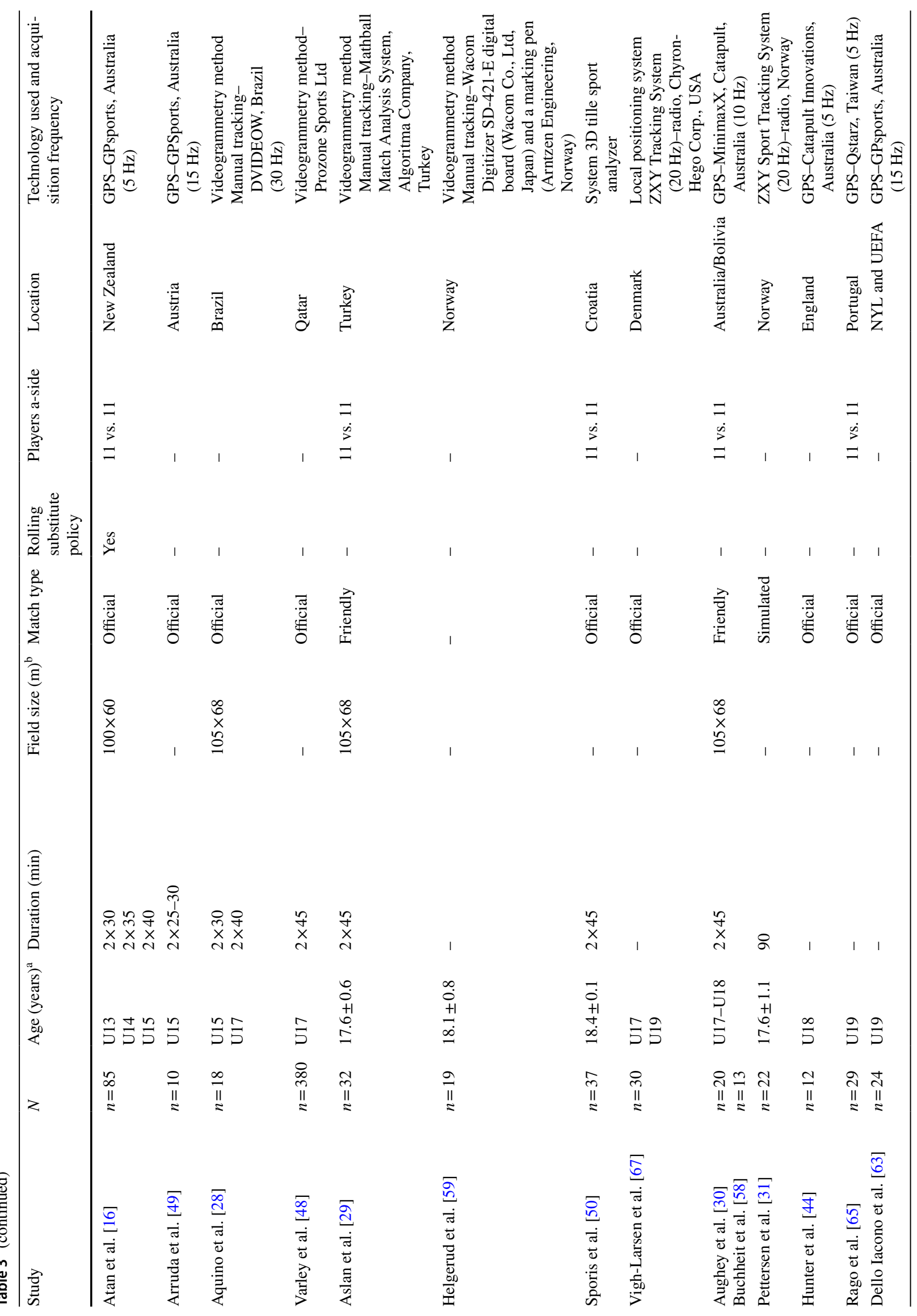




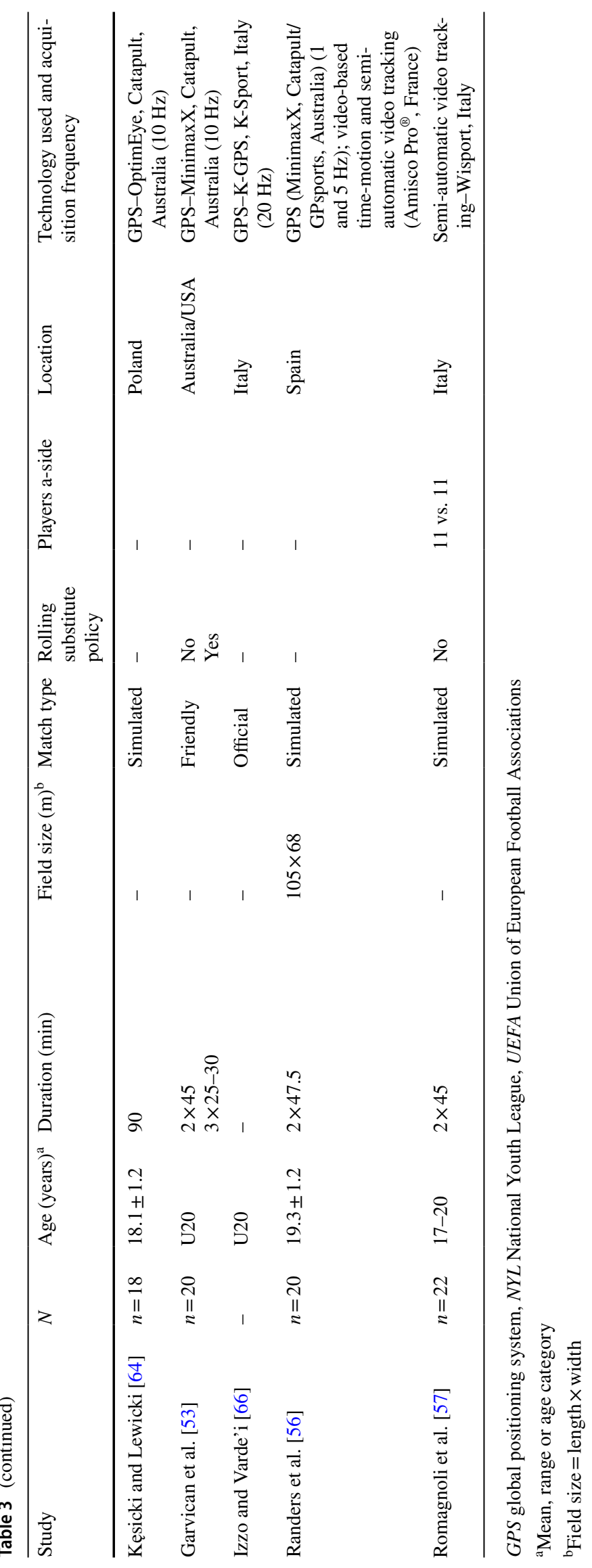




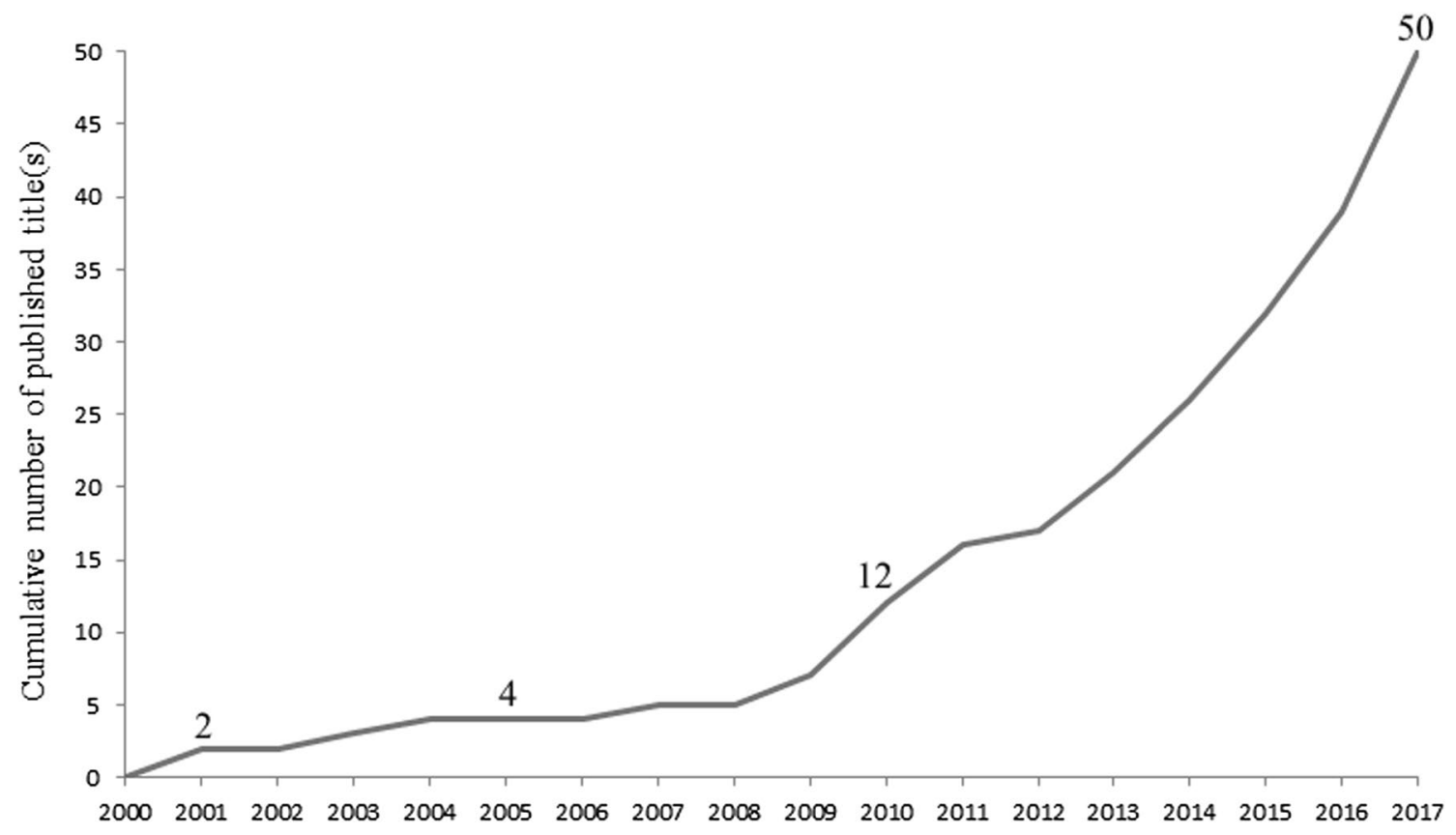

Fig. 2 Yearly distribution frequency and cumulative sum of the number of publications included in the current systematic review addressing match running performance in young soccer players

$18,23,24,28-33,39,40,42-46,48-57,60-62,65-67]$, whereas $14(28 \%)$ used individualized speed thresholds [12-17, 19, 20, 26, 29, 41, 42, 44, 47]. Nine studies (18\%) employed both methods [12, 15, 17, 29, 41, 42, $44,58,63]$. Three types of individualization techniques were reported: (1) speed thresholds derived according to individual physical capacity using data from fitness testing protocols (20\%) - these were generally based on maximal linear sprint speed, lactate concentrations, and $\mathrm{v} \dot{V} \mathrm{O}_{2 \max }$ tests [12, 14, 15, 17, 29, 41, 42, 44, 47, 58]; (2) thresholds proposed according to mean values for physical capacity (e.g., maximal linear sprint speed test) for each age group $(12 \%)[13,15,16,19,20,26]$; and (3) individual sprinting threshold using a percentage of individual peak game speed relative to an arbitrary fixed threshold $(25.2 \mathrm{~km} / \mathrm{h})$ [63]. Four remaining studies [27, $37,38,43$ ] were conducted using operator judgment of the intensities reached during running displacements (i.e., video-based time-motion [VTM]) performed by players in a given movement category. The number of speed thresholds used ranged from a minimum of one to a maximum of eight (ST1-ST8). There were 31 distinct arbitrary fixed speed thresholds, 26 distinct individualized speed thresholds by mean age-band physical capacity, and 11 distinct individualized speed thresholds by individual physical capacity employed to characterize the youth players' running performance (see Table 4).

\subsubsection{Technology}

In reference to the technologies utilized to quantify match running performance, 25 studies employed global positioning systems (GPS) exclusively (64\%), with sampling frequencies preset at $1 \mathrm{~Hz}(28 \%)[12,14,15,17-19,26,39-42,51,52$, 60], $5 \mathrm{~Hz}(14 \%)$ [13, 16, 19, 33, 44, 61, 65], $10 \mathrm{~Hz}(16 \%)$ [20, $30,46,47,53,54,62,64], 15 \mathrm{~Hz}[49,63]$ and $20 \mathrm{~Hz}[66]$. Among the remaining studies, four employed VTM [27, 37, 38,43 ], and eight used video tracking (i.e., videogrammetry) approaches (16\%), which were performed either manually [28, $29,59]$, semi-automatically [48, 57] or automatically $(30 \mathrm{~Hz})$ $[32,45]$, or the method was not stated [55]. One investigation compared $1 \mathrm{~Hz}$ GPS, $5 \mathrm{~Hz}$ GPS, VTM techniques and semiautomatic video-tracking methods [56]. Two studies did not provide sufficient information about their methodologies $[23,50]$. Castagna et al. [24] adopted a triangular surveying method (for more information see Carling et al. [4] and Ohashi et al. [72]), and two studies utilized a three-dimensional local radio processing system $(20 \mathrm{~Hz})[31,67]$.

\subsubsection{Terminology}

Nine distinct nomenclatures were used to the report the methodology used to obtain the running performance variables, ordered from the most to least frequent, as follows: (1) match analysis (36\%) $[12,15,16,19,24,26,27,29,31$, 


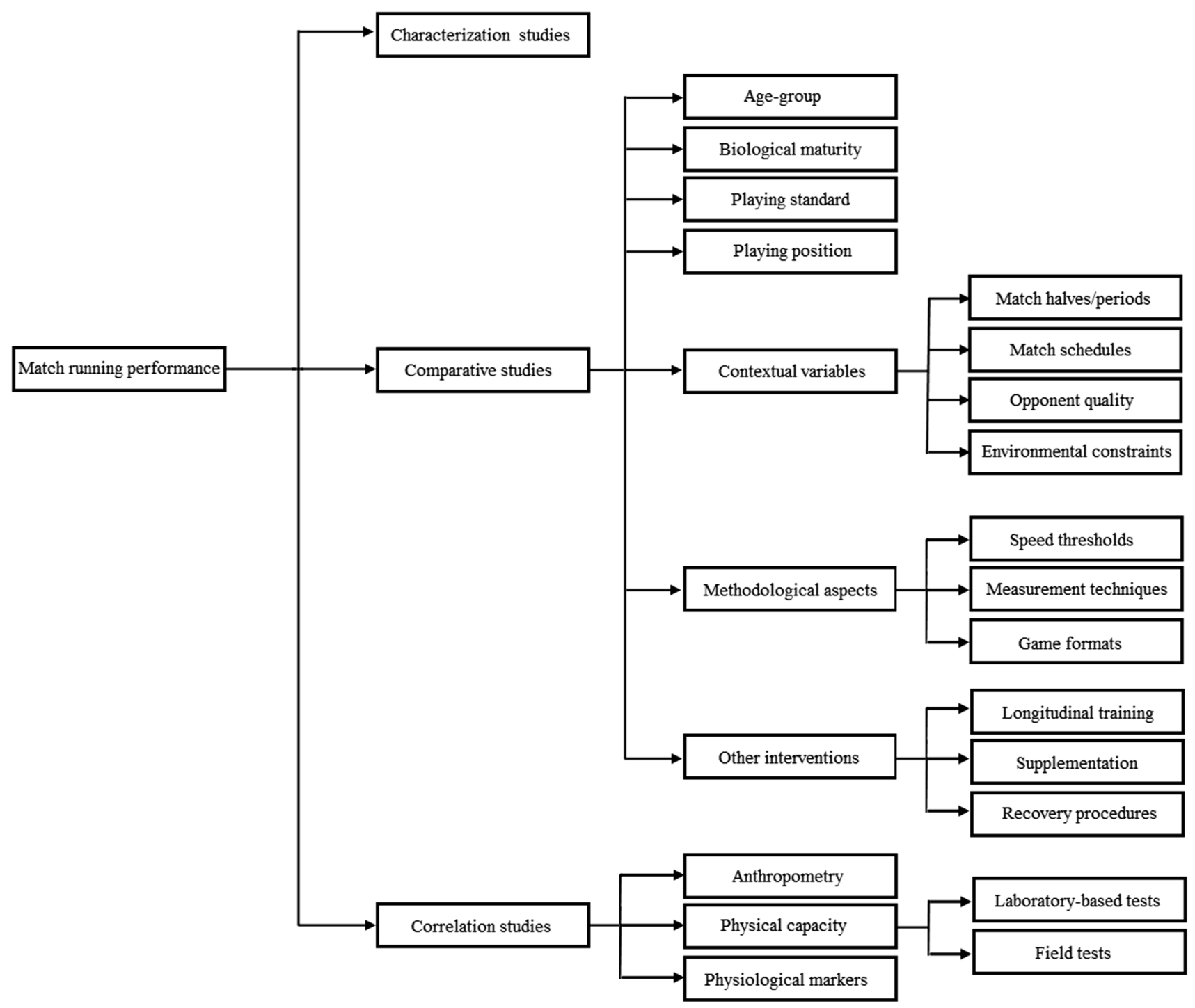

Fig. 3 Research topics of studies on match running performance in young soccer players

37, 41, 43, 44, 46, 51, 57, 60, 61]; (2) TMA (22\%) [12, 14, $17,18,41,42,44,51,56,62,65]$; (3) performance analysis [28, 32, 39, 52]; (4) motion analysis [13, 15, 16]; (5) kinematic analysis [23, 55]; (6) physical analysis [45]; (7) video analysis [59]; (8) movement analysis [33]; and (9) external load data collection [63]. To define and group dependent variables related to running performance, we verified 20 different descriptions, ordered from the most to least frequent, as follows: (1) match running performance (26\%) [14, 16-20, 28, 41, 42, 51, 52, 58, 60]; (2) match activities (24\%) [15, 16, 24, 26, 31, 33, 38-40, 43, 47, 50]; (3) activity profile (22\%) [24, 30, 31, 39, 40, 46, 53, 54, 56, 58, 67]; (4) distances covered (10\%) [13, 27, 57, 59, 64]; (5) physical performance [32, 40, 47, 48]; (6) movement patterns [27, 29, $32,65]$; (7) activity pattern [38, 41, 54]; (8) player's movements [37, 44, 48]; (9) physical loads [23, 40]; (10) physical match performance [43, 46]; (11) running performance [53]; (12) running activity [62]; (13) motor performances [23]; (14) displacement patterns [45]; (15) running measures [49]; (16) match intensity [58]; (17) match play intensity [14]; (18) running activity [41]; (19) physical variables [61]; (20) time-motion variables [63]; and unknown [55].

\subsection{Match Running Performance}

\subsubsection{Playing Standard}

For age-matched players (U13 and U14 categories), match running performance was greater in elite players (e.g., total distance covered, distance covered per minute, highintensity running, peak game speed) [33, 54]. Conversely, these players performed fewer standing or low-intensity 


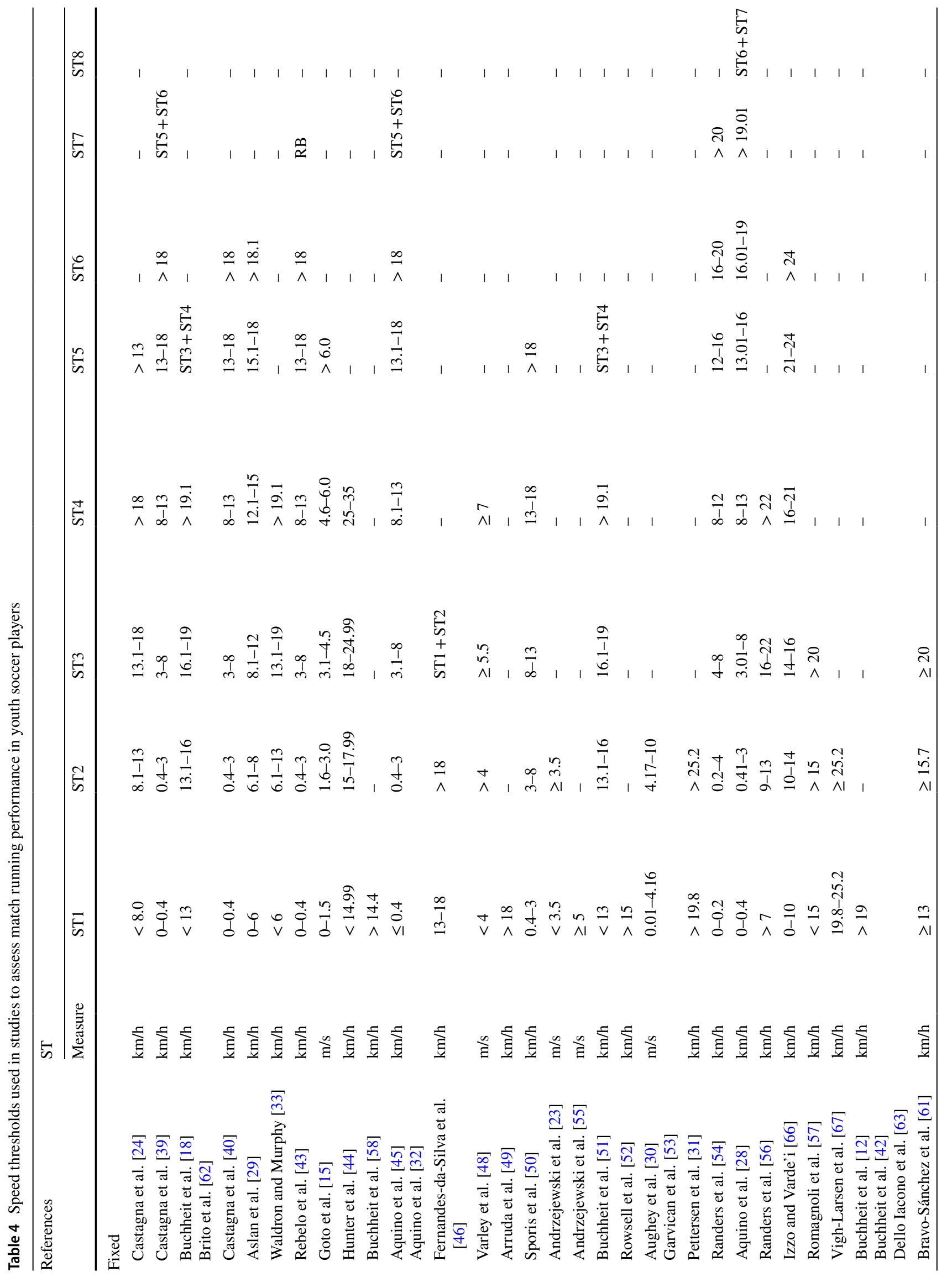




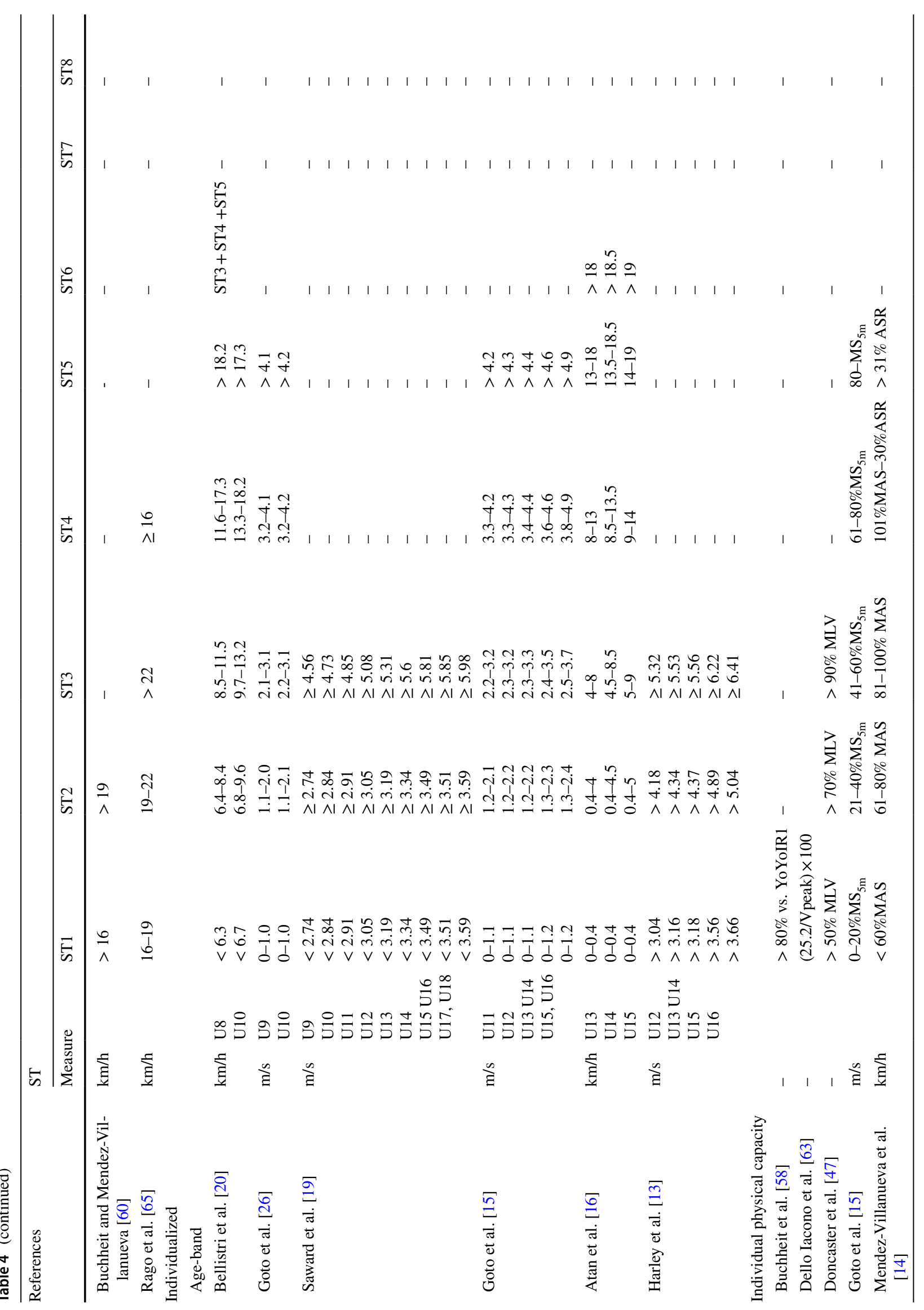




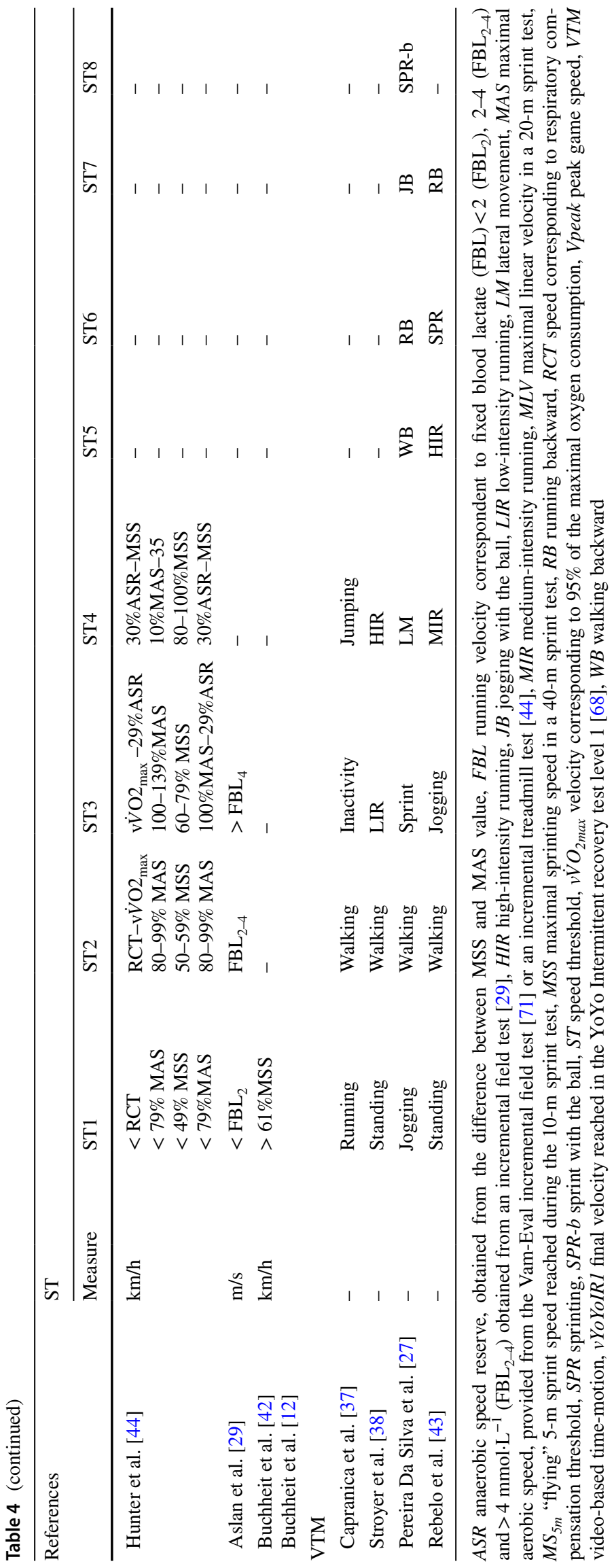


displacements $[33,38]$ than did nonelite or recreational peers. Studies also highlighted differences in match running performance, favoring academy players who were retained (e.g., greater distance covered per minute and low- to moderate-intensity running) compared with those released in some age groups $[15,19,26]$. In addition, a greater sprint distance was covered by top- and middle-ranked teams than by bottom-ranked U17 peers [48]. Table 5 summarizes the general match running performance results extracted from the reviewed papers. Indicators of running load included total distance covered, distance covered per minute, peak game speed reached and the distribution of distances covered according to speed thresholds.

\subsubsection{Match Halves}

Contrasting results regarding comparisons between halves were observed. Several studies ( 47\%) reported reductions in second-half measures of running performance (e.g., total distance covered, high-intensity running, repeated sprint sequences) [12, 14, 16, 29, 39, 40, 57]. In contrast, numerous articles (40\%) reported no changes (e.g., total distance covered, time spent in high-intensity running, high-intensity running distance) $[16,20,23,24,37,43]$, and two $(\sim 13 \%)$ identified an increase (e.g., average speed, high-intensity running, peak game speed and number of sprints) $[32,45]$ in match running performance during the second half.

\subsubsection{Age Group Comparisons}

Concerning age-related performance, the values for some parameters (e.g., peak game speed, total distance covered, repeated sprint sequences, high-intensity running, highintensity activities) were greater in the older than in the younger groups in cross-sectional studies [13-15, 17, 18, $20,67]$ that used fixed speed thresholds. In addition, older players performed more high-intensity actions than younger peers in the same U15 age group [60]. Age-related differences varied from slight [18] to large [15]. On the other hand, when individualized speed thresholds were applied or distances covered were adjusted by effective playing time, the differences were less evident $[12,13,15,16,18]$. While studies rarely identified greater running outputs in younger than in older players in absolute terms (e.g., distance covered per minute [27]), this finding was more frequent when individualized speed bands were employed (e.g., repeated sprint sequences and peak game speed relative to maximal sprinting speed in field tests, distance covered above maximal aerobic speed) $[12,14,16,17]$. In addition, players commencing puberty spent more time in standing/walking and lower jogging movements than did mature players [38]. There was evidence that more mature players achieved greater peak speeds and performed more high-intensity actions and repeated high-intensity actions in match-play than did less mature peers in the U15 category [60].

\subsubsection{Between-Position Differences}

Studies were in accordance that match running performance measures (e.g., total distance covered, peak game speed, frequency of sprints, sprinting distance) were position dependent $[12,14,17-19,23,27,29,41,42,48,62,65,66]$. Centre backs reported the lowest values for total distance covered [14] and high-intensity activities [18, 23, 48, 62]; midfielders and second forwards covered the highest total distance covered; wide midfielders and forwards demonstrated the highest peak game speeds and frequency of high-intensity activities $[17,18,66]$.

\subsubsection{Association with Physical and Physiological Factors}

Match running performance was moderately to strongly correlated with postmatch physiological markers (CK, LDH, cortisol, IL-6) in two studies [45, 57]. Positive relationships were also revealed on several occasions between match running performance (e.g., total distance covered, sprinting, high-intensity running, high-intensity activities) and physical capacity, as determined by the following tests: YoYo IR-1, YoYo IR-2, multistage fitness, Carminatti, 20-m shuttle run, Zig Zag, Hoff, RAST and 40-m sprint [17, 20, 28, $29,39,40,43,46,47]$. On the other hand, analysis across positional roles showed significant relationships between match running performance and physical capacity only in strikers and second strikers (e.g., very high-intensity match activities vs. Vam-Eval test [71]). Otherwise, nonsignificant trivial correlations were identified for fullbacks, center backs, midfielders and wide midfielders [18] (see an example of contrasting results in Rago et al. [65]). Similarly, low explanation power was revealed for several of the aforementioned tests (i.e., Zig-Zag Test, RAST, YoYo IR-1) used to predict match running performance (peak game speed, total distance covered, and percentage at velocity $8-13 \mathrm{~km} / \mathrm{h}$ ) $\left(R^{2}=17-22 \%\right)$ [28]. Additionally, $\dot{V} \mathrm{O}_{2 \max }$, whether estimated or directly determined, was not associated with match running performance in some papers [29,43], whereas in other papers, $\mathrm{VO}_{2}$ kinetics were significantly related to total distance covered and high-intensity running [47]. MendezVillanueva et al. [14] reported no significant relationships between match running performance (i.e., differences between first and second half) and physical capacity (i.e., maximal aerobic speed) determined using the Vam-Eval test, irrespective of playing position. There were also contrasting examples of correlation outcomes between match running performance and anthropometric measures. Nonsignificant (vs. body mass, height, body fat percentage) and weak to moderate correlations (vs. subscapular and abdominal 


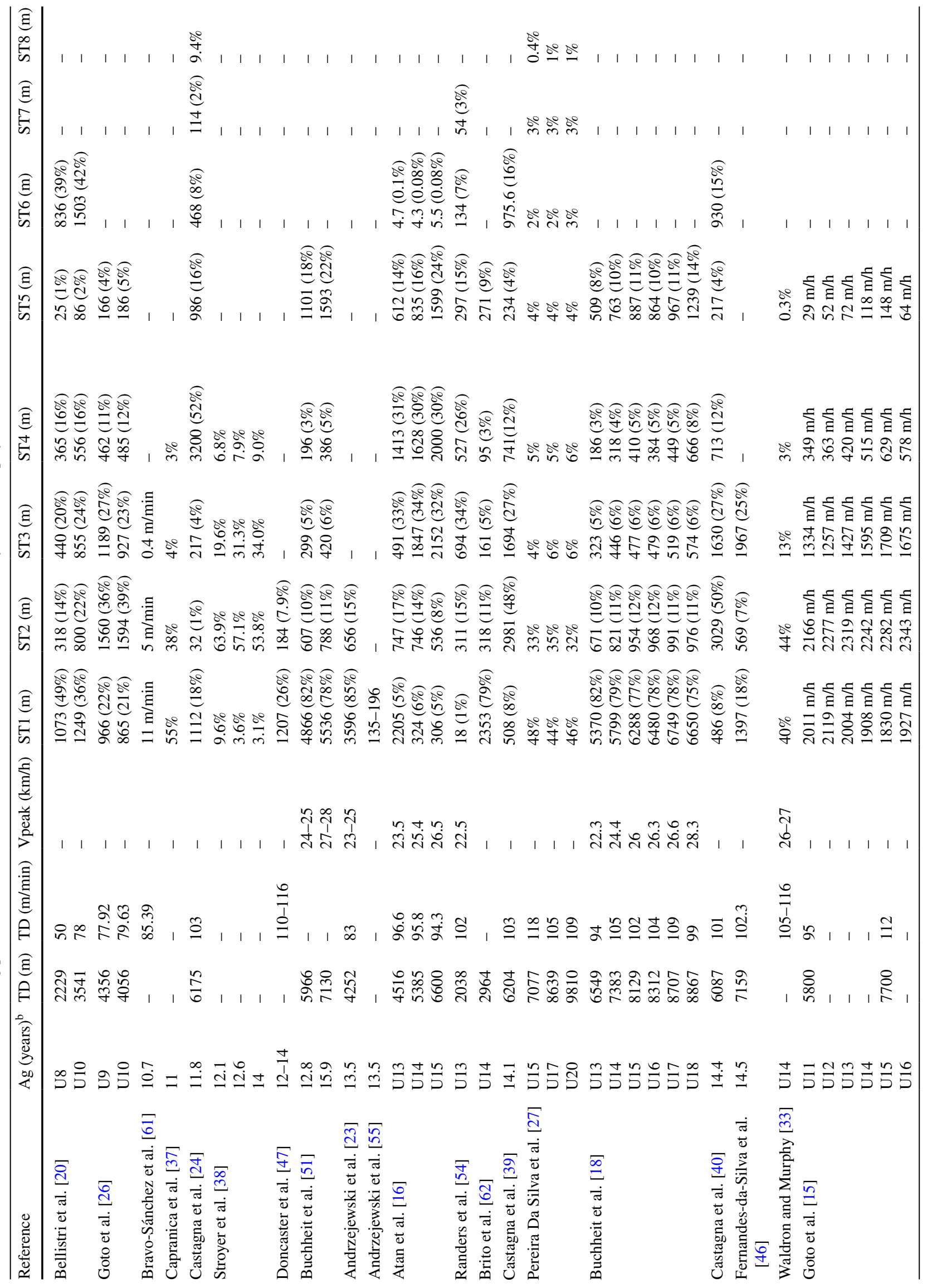




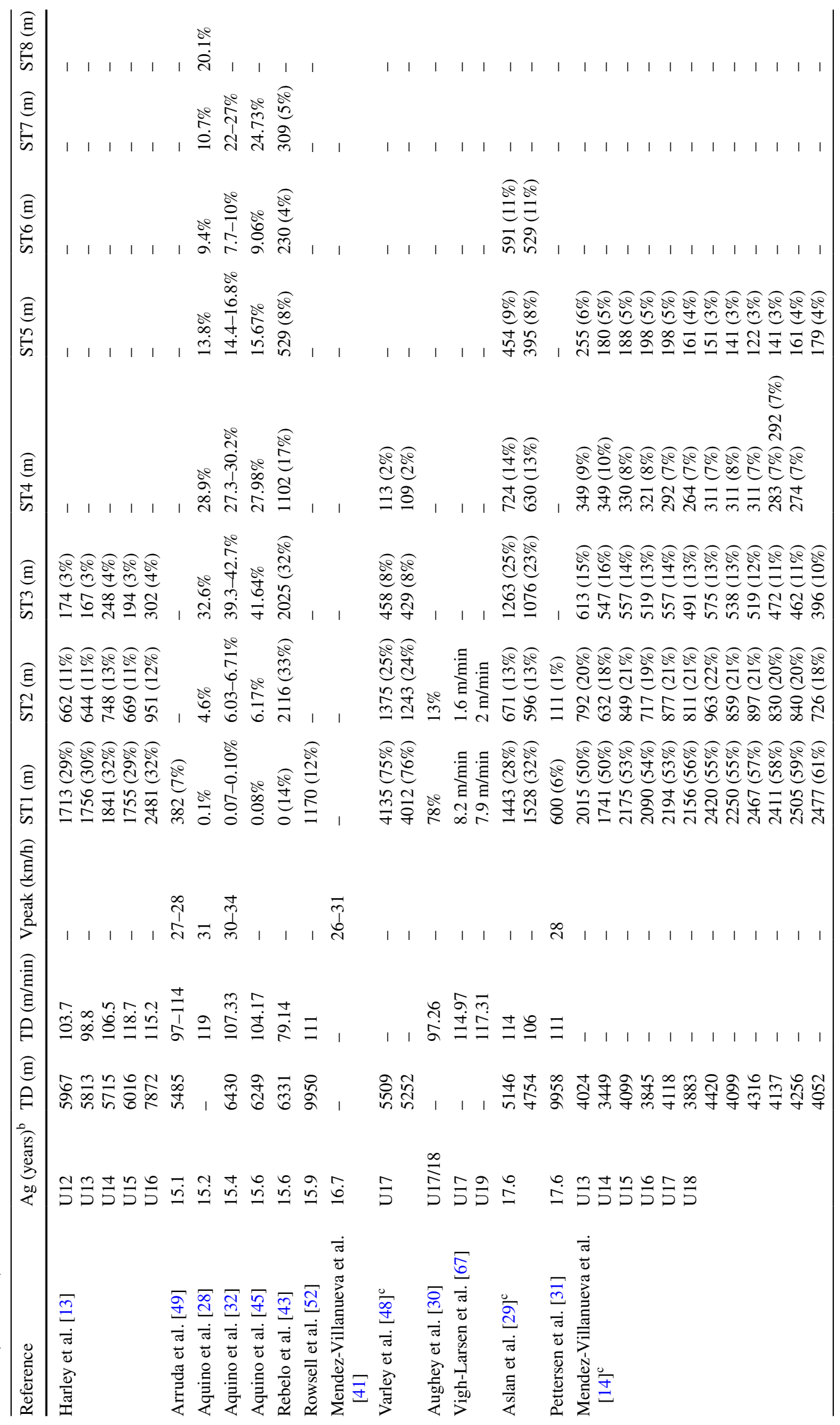




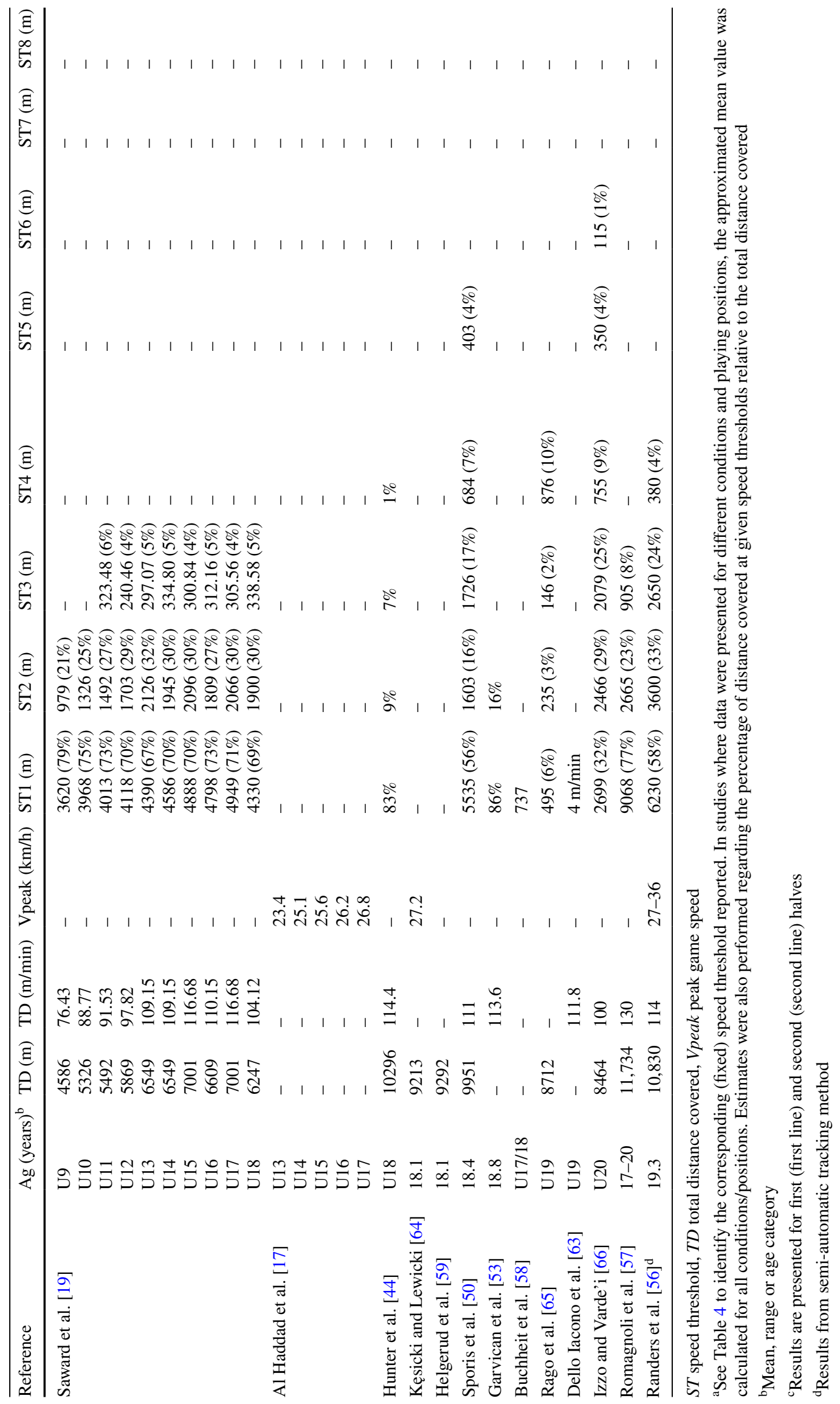


skinfolds) were found in all player positions when the data were pooled [50]. In contrast, wingers showed moderate to large relationships for high-intensity running variables combined with body mass and height [60].

\subsubsection{Environmental Constraints}

Four studies assessed the possible effects of environment factors on match running performance in young soccer players. Locations with moderate (Denver, USA; $1600 \mathrm{~m}$ ) [53] or high altitude (La Paz, Bolivia; $3600 \mathrm{~m}$ ) [30, 58] had detrimental effects on match running performance (e.g., distance covered per minute, high-intensity activities) compared with sea level, regardless of where players were born/living. A single study assessing the effects of pitch surface identified slightly to moderately greater demands (total distance covered and very high-intensity running) when competing on artificial versus natural turf [62].

\subsubsection{Congested Match Schedules}

Three studies investigated congested match schedules. First, Buchheit et al. [51] showed that, in post peak height velocity (PHV) players ( $15.9 \pm 1$ year), two successive matches played within $48 \mathrm{~h}$ resulted in impaired running performance in the second fixture, whereas this was not the case in prePHV players (12.8 \pm 0.6 years). Similarly, Rowsell et al. [52] observed decrements in match running performance over the course of four matches played in a 4-day period in players with a mean age of 15.9 years. In contrast, Arruda et al. [49] did not observe differences regarding total distance covered, distance covered per minute, high-intensity running efforts and distance, and body-load impacts (which had higher values in the final than in other matches) in U15 players (mean age 15.1 years) across five matches played over a 3-day competitive period. In contrast, the absolute frequency of accelerations $\left(>1.8 \mathrm{~m} / \mathrm{s}^{2}\right)$ and accelerations per minute decreased over the course of the competition.

\subsubsection{Recovery Methods}

Two studies assessed the impact of postmatch recovery strategies on match running performance. Spa treatment ( $2 \mathrm{~min}$ hot shower at $33-43{ }^{\circ} \mathrm{C}+$ three times [sequence of $2 \mathrm{~min}$ sauna at $85-90{ }^{\circ} \mathrm{C}, 2-\mathrm{min}$ jacuzzi/hydromassage at $36 \pm 1.5$ ${ }^{\circ} \mathrm{C}$ and cold water immersion at $\left.\sim 12 \pm 1{ }^{\circ} \mathrm{C}\right]$ ) in post-PHVs with a mean age of 15.4 years [51] or only cold water immersion $\left(5 \times 1 \mathrm{~min}\right.$ at $10^{\circ} \mathrm{C}$ ) (players with a mean age of 15.9 years) [52] were associated with beneficial effects on subsequent match running performance output such as total distance covered, sprinting distance, repeated-sprint sequences and peak game speed. Additionally, a single publication evaluated the effects of supplementation on match running performance in youth soccer. In this sense, caffeine supplementation $\left(6 \mathrm{mg} \cdot \mathrm{kg}^{-1}\right)$ did not enhance running output in players with a mean age of 17.6 years [31].

\subsubsection{Comparisons Between Formal Games and Other Game Types}

Two studies compared 11 versus 11 (i.e., formal match-play) with other game formats (i.e., small-sided games). Capranica et al. [37] observed no differences on TMA variables, including running (forward, backwards and with the ball), walking (forwards, backwards and sideways) and inactivity (no locomotion) between 11 versus 11 (field size $100 \times 65 \mathrm{~m}$ ) and 7 versus $7(60 \times 40 \mathrm{~m})$ in 11-year-old players. In contrast, Randers et al. [54] reported that 11 versus $11(105 \times 68 \mathrm{~m})$ resulted in a greater total distance covered, peak game speed and distances in several speed bands (e.g., $>4 \mathrm{~km} / \mathrm{h}$ ) than 8 versus $8(52.5 \times 68 \mathrm{~m})$ in a sample of U13 players. Official U12 7-a-side matches were more demanding (i.e., greater total, high-intensity, very high-intensity and sprint distances) than 8 -a-side, size-matched $(40 \times 60 \mathrm{~m})$ games. An additional study comparing official U19 matches and game profile-based training sessions $(3 \times 8$-min bouts including $30 \mathrm{~s}$ of physical and technical exercises at $50-75-105 \%$ vYoYoIR1, followed by $30 \mathrm{~s}$ of active recovery) revealed lower total and high-speed distances covered per minute and fewer high-intensity efforts in the former than in training [63].

\subsubsection{Longitudinal Interventions}

Four articles were longitudinal intervention studies. After periodization training ( 22 weeks), emphasizing technicaltactical ability, U16 players showed an increase in running performance, mainly in peak game speed and high-intensity activities during simulated matches (players from all positions grouped together) [32]. Buchheit et al. [42] demonstrated that seasonal changes ( 7 months) in running performance during friendly matches (i.e., repeated sprint sequences and repeated high-speed running sequences) were position dependent in U13-U16s. Andrzejewski et al. [55] divided players (mean age 13.5 years) into two groups (endurance group $\leq$ average sprint test performance $<$ speed group) in which "speed-type" players participated in training sessions of bouts of 9-17 m, whereas "endurance-type" players ran 4-9 m (with 40-60 and 25-50 s for recovery, respectively). After a 6-month macrocycle, the former group performed more sprints and distance $\geq 5 \mathrm{~m} / \mathrm{s}$ during match play but covered a lower total distance than their endurancetype peers [55]. Finally, Helgerud et al. [59] reported an increase in the total distance covered and number of sprints in players with a mean age of 18.1 years after an 8-week training regimen consisting of regular (match play, technical, tactical, strength and sprint training) plus aerobic interval 
training. The control group, for whom training involved only regular and additional technical training, did not experience similar improvements.

\section{Discussion}

The purpose of the present analysis was to systematically review the body of knowledge available on match running performance measures in young male soccer players. A total of 50 studies provided reference data from 17 different geographical locations. Most studies examined official match play, a broad range of chronological ages and, occasionally, positional roles. Hence, a reasonable amount of knowledge exists, although a lack of interventions that directly impacted training and preparation was evident. This discrepancy may be due to most of the research conducted being relatively recent (Fig. 2). Nevertheless, the available information contributes to the understanding of game requirements and can inform training content for physical conditioning sessions [73]. Here, the strengths and limitations of the current literature are discussed, and recommendations are made for further investigation.

\subsection{Methodological Quality}

Overall, the identified research articles generally presented high methodological quality ratings $(79 \pm 13 \%$; Table 2$)$. The questions with the highest mean rating, taking into account all included studies, were Q1 and Q5, suggesting that the literature aims and the dependent variables that were analyzed were generally clearly set out. In contrast, Q4 exhibited the lowest mean quality score. This highlights that essential characteristics of the time-motion system/equipment used were either unaccounted for and/or lacking in the text. This issue is explored in Sect. 4.2.5, where measurement techniques are discussed.

\subsection{Research Paradigm}

\subsubsection{Location of Player Populations}

An analysis of the geographical location of populations showed that almost all continents were represented. The greater portion of studies concerned European countriesparticularly England—and also Qatar, with a recent trend for an increase in the number of publications in South America. No scientific studies were identified from African countries, clearly indicating a need for research in youth populations in these countries.

\subsubsection{Player Categorization}

An issue requiring further debate is the definition of criteria for categorizing youth players in soccer competitions for research purposes. As such, the majority of the scientific evidence observed used comparisons based on chronological age cutoff points. Studies in England [13, 15, 19, 26] and New Zealand [16] used 12-month age bands, according to the Premier League [74] and Auckland Football Federation regulations [75], respectively. Studies in the São Paulo State Championship (i.e., the leading state-level tournament in Brazil [32]) adopted age banding with 24-month cutoff points [3, 27, 28], similar to that employed in Italian youth competitions [20], according to Federazione Italiana Giuoco Calcio standards [76].

It is important to highlight that, in chronologically agematched individuals, those demonstrating advanced biological maturity status can have an advantage in anthropometric (weight and height) and physical ability (aerobic resistance, sprint and jump performance) indicators over their less mature peers [77]. The same point is valid for match running performance. Indeed, Buchheit and Mendez-Villanueva [60] reported slightly to moderately greater peak game speed, high-intensity actions $(>19 \mathrm{~km} / \mathrm{h})$ and repeated high-intensity actions (two $>19-\mathrm{km} / \mathrm{h}$ runs interspersed by a maximum of $60 \mathrm{~s}$ ) in more mature than in less mature players, both belonging to the same U15 group. Goto et al. [78] reported similar results in U13/U14 players. Recently, Cumming et al. [79] analyzed the effects of a BioBanded soccer tournament (i.e., games played by youth [U12-U15] players having $85-90 \%$ of predicted adult stature) and reported that players had a positive perception toward such practice compared with usual age group competitions. Early and late maturing players deemed the matches as more and less physically challenging, respectively. Future studies are necessary to assess match running performance using TMA in BioBanded players.

\subsubsection{Match Type and Configurations}

Simulated soccer matches can generate physiological responses that differ from those in official competition. However, no studies have directly compared match running measures among different soccer match play modalities (e.g., simulated, friendly, preseason tournament vs. official). Freitas et al. [80] reported that psychophysiological stress was greater during official competition than during a simulated game, and a lower reduced internal workload (e.g., session rating of perceived exertion) was also observed in the latter. Hence, caution is necessary when using running data from simulated and friendly matches to determine competition demands and inform physical preparation regimens. 
In general, standardization was lacking across study designs in age-matched players, particularly with respect to game configurations. For example, pitch sizes, game durations, division of playing periods, the number of players per side, and rolling substitute policy application varied considerably (see Table 3) [3]. Variations in the aforementioned parameters have been shown to influence on-field running performance in soccer match play [54, 81, 82]. As such, conditioning practitioners working in youth soccer should consider that data published for a given population may not be pertinent for another.

\subsubsection{Speed Thresholds}

The absence of standardization in speed thresholds (see Table 4) across the literature makes it difficult to compare findings on running output [44]. Nevertheless, the use of fixed speed thresholds does provide useful information regarding player development (e.g., comparisons between age groups) and the effects of training on match running performance [15, 32, 42]. In addition, fixed speed thresholds allow direct outcome comparisons between studies [18]. However, several authors suggest that individualizing speed thresholds provides a more accurate representation of match running loads in young soccer players [13, 16, 44]. This practice can also aid individualized assessments and comparisons between players of differing maturational levels [16] and management of external workloads through the design of appropriate recovery and periodization schedules [44].

The majority of studies employed field testing procedures, such as linear sprint speed [13-17, 19, 20, 26, 47], as a means to determine age-specific or individualized speed thresholds. Yet, recent evidence suggests that maximal sprinting speed has limitations for establishing game speed thresholds for several reasons: (1) peak game speed values might exceed those derived from tests of maximal sprinting speed [83]; (2) individualized game speed thresholds do not enhance the dose-response determination to soccer training $[44,84]$; and (3) seasonal changes in match running performance do not necessarily match those observed in sprinting test performance; players with decreased maximal sprinting speed demonstrated concomitantly increased match running performance (e.g., number of repeated sprint sequences and repeated-high speed sequences) [42]. Although two of the above-cited studies were not specifically performed in youth [83] and males [84], further investigations are required to assess the relevance of creating speed thresholds from game parameters per se to depict match running performance. A comparison of speed thresholds as a percentage of peak game speed and distances covered in fixed speed thresholds relative to total distance covered $[3,63]$, rather than using fitness testing performance to determine speed thresholds, would be useful.

\subsubsection{Measurement Techniques}

A key study by Randers et al. [56] compared data derived from GPS-based technologies, VTM and computational videogrammetry tracking techniques. Large between-system differences were present in the determination of the absolute distances covered, meaning that results between match analysis systems should be compared with caution [56]. Indeed, a wide variety of data acquisition methods was employed across studies (see Table 3). GPS is considered the most time-efficient method to collect and report match data in contemporary soccer [85]. Yet, most studies (42\%) used low sampling frequency GPS devices (i.e., $1-5 \mathrm{~Hz}$ ), which exhibit consequential error rates in determining high-speed activity [86]. Computer-based tracking adopted in investigations in youth players (e.g., Prozone ${ }^{\circledR}[48,87]$, Mathball Match Analysis System [29] and DVIDEOW ${ }^{\text {TM }}$ [28, 32, 45]) show low absolute error [3, 21, 29, 88]. Indeed, when compared with GPS and local position measurement, videogrammetry tracking methods are shown to have the most constant magnitude of error in computing distances when running occurs at low- and high-intensity speed thresholds [85]. However, logistical constraints can favor the use of GPS, especially when youth matches take place in training ground facilities [3, 13, 48].

Specific issues affect TMA data collection: (1) for GPS: the environment (e.g., topography), number of satellites connected and software/unit updates; and (2) for computerbased tracking: lighting, background objects, camera position and calibration quality. All these issues can interfere with data signal [85, 86, 89-91], and measurement error should ideally be calculated in the locations where matches are specifically played, a factor that was systematically overlooked in the current literature (see Table 2).

\subsubsection{Terminology Issues}

A total of 20 descriptors were adopted among studies included in the current systematic review to define and group dependent variables (e.g., total distance covered, mean speed or distance covered per time, peak game speed, indicators of activities performed at established speed thresholds or movement categories). Thus, there is a need to standardize terminology in this research area. To make it easier for readers to identify evidence related to this research area topic in the future, we suggest the authors simply use "match running performance", as this was the most cited term-used approximately $26 \%$ of the time-in the published articles. 


\subsection{Match Running Performance}

\subsubsection{Playing Standards}

Match running performance metrics were used to discriminate youth players across different competitive standards (elite, nonelite and recreational) and status (retained and released from an academy). It is necessary to appraise these results in relation to talent identification and development. Conclusions drawn in some studies have received criticism mainly because of methodological flaws (e.g., accounting for the effect of biological maturity and/ or relative age) [73]. Choices on whether or not youth players should be retained in a soccer academy cannot be based solely on match running performance data. Indeed, a holistic approach to evaluating young players is necessary to prevent one-dimensional insights into competitive performance [92]. This includes the integration of running performance analyses in a model including technical, tactical, decision making and anticipation measures [3, 73, 93]. Yet, obtaining information on technical measures and quantifying the tactical aspects of the game can be challenging [94]. Of all the publications examined in the current systematic review (i.e., $N=50)$, only nine $(18 \%)$ performed an analysis of running performance concomitantly with other match-related performance variables, i.e., technical [33, 48, 54, 59, 61, 62] or tactical [24, 32, 45].

\subsubsection{Playing Positions}

The present literature showed that match running performance is position dependent in young soccer players. In general, studies analyzed match running performance (e.g., sprinting distance) across playing positions, adjusting the data for age and playing time (e.g., Mendez-Villanueva et al. [14], Buchheit et al. [18], Varley et al. [48]). However, a major concern is the extent to which the differences presented in the literature $[12,14,18,41]$ are meaningful and can be used to inform subsequent position-specific training regimens [93]. For example, one of the few studies that expressed sprinting distance relative to total distance covered revealed differences of $<2 \%$ across outfield playing positions in young soccer players aged U15-U20 [27]. A fundamental question left unanswered in the literature is: Are there meaningful differences between playing positions across all youth categories? Since match running performance is age dependent (see Sect. 4.3.3), addressing this gap could help practitioners determine the age(s) at which additional training to develop running ability is necessary for the most demanding positional roles.

\subsubsection{Age-Related Performance}

Match running performance determined using fixed speed thresholds increased concomitantly with age. In theory, therefore, designing conditioning sessions on the basis of actual match load means that the training of running capability should be progressively adjusted according to age across all categories. However, when using age-specific or individualized speed thresholds, discrepancies in results compared with fixed speed thresholds were identified. A trend for greater relative match running performance (e.g., peak game speed, distance covered in high-intensity running) was observed in younger than in older players $[14,16,17]$. The authors suggested this was due to a lower technical-tactical game understanding in younger players $[3,14,16,17]$. In addition, it is necessary to avoid generalizations regarding changes in match running performance [3], since differences between age groups were accompanied by effect sizes ranging from small to large across the studies.

\subsubsection{Between-Halves Comparisons}

To date, there is an evident lack of agreement across studies on the occurrence of reductions in match running performance in age-matched youth players over the course of play. For example, it has been suggested that age groups that are pre-PHV will have unchanged or only slightly decreased running performance over the match because of lower running outputs at high intensities, whereas age groups that are postPHV will exhibit reductions in running performance [3]. However, contrasting evidence exists, as some studies report that running outputs in pre-PHV age groups remained similar throughout match play [3, 16, 20,24], whereas declines were observed in others [12,14]. Similarly, no decrements were reported in post-PHV age groups [32, 43, 45]. Thus, the occurrence of reductions in running performance over the course of play does not appear to depend upon the PHV of the age group. Analysis of the literature needs to consider whether changes in between-half performance depends upon the duration of the halves [3] and/or the effective playing time [95]. Additional investigations of the effects of contextual factors, such as game rules, match type, format and configuration, situational and environmental factors (e.g., see Aquino et al. [45]) are also warranted.

\subsubsection{Association with Physical and Physiological Factors}

Significant relationships were observed between the total distance covered, high-intensity and sprinting distances and physiological markers of muscle damage prematch, immediately after (CK, LDH and IL-6) and $48 \mathrm{~h}$ (cortisol) postmatch. Biochemical measures are potentially useful when monitoring the effects of running output on recovery status 
$[45,57]$. Body size appeared to be associated with match running performance output according to positional role but not when all positions were pooled, although only limited evidence was found $[50,60]$. In contrast, over one-fourth of the entire literature was dedicated to understanding the physical capacity-match running performance relationship. In general, studies assessed the construct validity of a given test. To date, findings on this research issue are inconsistent (see Sect. 3.4.5). Yet, of 12 articles that investigated the association between physical capacity and match running performance, only four [14, 17, 18, 65] accounted for playing position. Moreover, the extent to which fitness tests can aid training prescription and predict match running performance in youth soccer is debatable (for more information see Mendez-Villanueva and Buchheit [96]).

\subsubsection{Environmental Constraints}

To date, the effects of altitude $[30,53,58]$ and pitch surface [62] on match running performance are the only environmental factors that have been investigated in youth soccer players. However, when this information was reported, environmental conditions varied substantially among studies (e.g., the temperatures ranged from $9.4{ }^{\circ} \mathrm{C}$ [33] to $36^{\circ} \mathrm{C}$ [52]), and ambient temperature was reported in less than half of the studies (36\%) [14, 16-18, 20, 28, 29, 31, 33, 39, 40, $42,45,47,48,50,52,56]$. In professional senior players, for example, a negative relationship between distances run at speed $>14 \mathrm{~km} / \mathrm{h}$ and environmental wet-bulb globe temperature has been reported [97]. Extreme conditions causing heat and cold stress can predispose children and youth to harmful effects more than in adults (e.g., greater water loss, increased heat production and lower locomotive economy) [98]. Future research should consider the potential effects of environmental conditions on youth soccer match play, and information on these should be systematically reported.

\subsubsection{Congested Match Schedules}

In professional senior soccer, most of the literature has reported no deleterious effects of congested match schedules on match running performance [8, 99-101]. However, recent evidence has shown that participation in congested fixture schedules (e.g., two matches in the same week vs. only one match) negatively influenced match running performance in U23 players (from individualized analysis) [87]. Similar findings were also reported for youth players (mean age $\sim 15-16$ years) when playing two matches in $48 \mathrm{~h}$, during a 4-day tournament with one match per day, and in five matches played over 3 successive days [49, 51, 52]. While performance in post-PHV players (mean age $\sim 16$ years) was negatively affected when playing successive matches, this was not the case for players with a mean age of $\sim 13$ years (i.e., pre-PHV players) [51]. Two studies that also observed reductions from congested schedules (mean player ages: $15.1 \pm 0.2$ and $15.9 \pm 0.6$ years $[49,52])$ did not account for maturity. It can be speculated that these populations were composed of circum- (and mainly) post-PHV individuals, with very few pre-PHV individuals (for example, see Buchheit and Mendez-Villanueva [102]).

Limited evidence exists on strategies and postmatch recovery interventions to reduce decrements in match running performance during periods of match congestion. Squad rotation and systematic monitoring of performance have been recommended [87, 91]. Postmatch cold water immersion and spa treatment demonstrated beneficial effects on subsequent match running output, particularly in young players near or after the growth spurt $[51,52]$.

\subsubsection{Longitudinal Training Interventions}

Little research was found regarding the effects of different training interventions on match running performance in youth soccer. Only approximately $10 \%$ (five publications) in the current literature addressed longitudinal experimental approaches to the problem. Of these, two did not clearly state the match type $[55,59]$ or describe in detail the intervention results (e.g., pre and post outcomes) [55]. Another paper examined age-related changes in match running performance [19]. In applied settings, obtaining repeated measures of match performance in youth players is challenging. Nevertheless, the current results from longitudinal intervention studies demonstrate that young soccer players positively respond to a deliberate training stimulus, which improves their running performance during simulated/ friendly matches. Interventions included periodization training ( $\sim 14 \mathrm{~h}$ per week in addition to competitive play) with technical-tactical emphasis (38-50\% of total training time; six to eight soccer training sessions per week) plus strength (15-23\% of total training time; one session per week) and conditioning sessions (35-41\% coordination-flexibility/ speed/aerobic power; one to two sessions per week) [32, 42]. Additional investigations are necessary to compare the results of interventions on performance during official competition.

\subsection{Limitations and Recommendations for Future Research}

Over the course of this review, several limitations of the current literature were identified. These include (1) $28 \%$ of included studies did not demonstrate an appropriate level of quality, (2) some of the research topics (e.g., in reference to Sects. 3.4.8 and 3.4.9) and derived systematic conclusions were drawn from a limited number of studies, (3) a lack of conformity as a wide range of different measurement 
systems were used, and (4) information on measurement error in obtaining running metrics was systematically overlooked.

Another key limitation across the studies that warrants discussion is the general lack of information concerning contextual variables (e.g., match location, quality of opponents, match status, result, fixture congestion), especially in comparison with the literature in professional senior players [6]. Indeed, congested match schedules have been shown to negatively affect match running performance in youth soccer, but at professional standards this is also dependent upon the specific team formation, match status and location [91]. While Varley et al. [48] showed that opposition quality can influence match running performance, additional research is merited to investigate other factors, including tactical elements (e.g., team and opponent formation), match context (location (home, away, neutral), match status (win, draw, loss, goal differential [20, 103]) and logistics (air/ground travel) on running performance indicators in youth soccer match play. The concomitant collection and analysis of verbalized coaching staff approach (e.g., adjustments in team tactical style), possible referee bias and crowd size would also be useful [104]. Other underexplored areas with potential practical applications include analysis of the possible effectiveness on performance of specific warm-up methods (e.g., postactivation potentiation via strength exercises [105]), nutritional strategies (e.g., supplementation with $\beta$-alanine [106], the effects of fasting during Ramadan), postmatch recovery techniques (e.g., active recovery, stretching, massage, sleep [107]) and the short- to long-term responsiveness to different training stimuli (e.g., high-intensity interval training) or even detraining.

Regarding data analysis, the inclusion of acceleration metrics would provide additional pertinent information to that of conventional measures (e.g., total distance covered, high-intensity and sprint distances), since hard accelerations and decelerations can occur even at low-intensity speed thresholds [67]. However, these were reported in only $20 \%$ of publications [30, 31, 49, 53, 54, 61, 63, 64, 66, 67]. Importantly, there is a general lack of information using an integrated approach that focuses on sensitive metrics such as high-intensity running, but contextualizes these in relation to key tactical activities for each position and collectively for the team [94], in order to develop a holistic approach to understanding match running performance of young soccer players. Furthermore, while still under debate [108], contemporary probabilistic statistics (e.g., magnitude-based inferences [MBI]) [109] were reported by only approximately $26 \%$ of the articles that were reviewed in the present analysis [14, 17, 18, 30, 41, 42, 44, 47, 48, 51, 53, 58, 60]. MBI (i.e., qualitative probabilistic mechanistic inference about the true change [58]) is suited to athletic performance and small sample sizes, and bias may be less than when traditional null hypothesis significance tests are used [109-111]. Nevertheless, normative values of the smallest worthwhile changes regarding match running performance still need to be determined [112].

\section{Conclusions}

The present study compiled current empirical evidence on match running performance in young male soccer players. Physical conditioning professionals should be aware of reference data of match running performance-when available- to inform conditioning programs for young soccer players on the basis of actual match demands. It is necessary to plan and adjust training according to players' development stage and age category as match running performance depends on maturity and age $[13-15,17,18,20,38,51$, 60, 67]. Game rules (e.g., criteria for grouping players, rolling substitute policy), match format and configuration (e.g., number of players per side, pitch size, match duration, number of periods) are almost completely unstandardized in studies of age-matched players. Thus, coaches working with youth development programs should consider that normative data for a given population may not be relevant to all other populations. Despite limited evidence, it appears that periodization training emphasizing technical-tactical content can improve match running performance [32, 42]. Information from laboratory and field fitness tests should be used with caution to predict running performance, especially as evidence supporting the construct validity of such tools does not account for playing position. Evidence for residual (during fixture congestion) [49, 51, 52] and acute (over the course of a match) $[12,14,16,29,39,40,57]$ decrements in running performance is common. The existence of residual decrements was more consistent across studies than were acute declines and is more likely to be dependent upon the maturity stage of the player. While additional research is necessary, the prescription of postmatch recovery strategies, including cold water immersion and spa treatments, have demonstrated positive findings $[51,52]$ in tempering the reductions in match running performance.

\section{Compliance with Ethical Standards}

Funding This study was funded by the Federal Agency for Support and Evaluation of Graduate Education (CAPES), National Council for Scientific and Technological Development (CNPq) (Grant 481833/20137) and São Paulo Research Foundation-FAPESP (Grant numbers 2016/50250-1, 2017/20945-0 and 2018/02965-7).

Conflict of interest Luiz Henrique Palucci Vieira, Christopher Carling, Fabio Augusto Barbieri, Rodrigo Aquino and Paulo Roberto Pereira Santiago have no conflicts of interest relevant to the content of this review. 


\section{References}

1. Williams AM, Reilly T. Talent identification and development in soccer. J Sports Sci. 2000;18(9):657-67. https://doi. org/10.1080/02640410050120041.

2. Unnithan V, White J, Georgiou A, Iga J, Drust B. Talent identification in youth soccer. J Sports Sci. 2012;30(15):1719-26. https ://doi.org/10.1080/02640414.2012.731515.

3. Palucci Vieira LH, Aquino R, Moura FA, Barros RML, Arpini VM, Oliveira LP, et al. Team dynamics, running, and skillrelated performances of Brazilian U11 to professional soccer players during official matches. J Strength Cond Res. 2018. https ://doi.org/10.1519/JSC0000000000002577 (Ahead of print).

4. Carling C, Bloomfield J, Nelsen L, Reilly T. The role of motion analysis in elite soccer: contemporary performance measurement techniques and work rate data. Sports Med. 2008;38(10):839-62.

5. Mohr M, Krustrup P, Bangsbo J. Fatigue in soccer: a brief review. J Sports Sci. 2005;23(6):593-9. https://doi.org/10.1080/02640 410400021286.

6. Sarmento H, Marcelino R, Anguera MT, CampaniÇo J, Matos N, LeitẪo JC. Match analysis in football: a systematic review. J Sports Sci. 2014;32(20):1831-43. https://doi.org/10.1080/02640 414.2014.898852.

7. Lago-Peñas $C$. The role of situational variables in analysing physical performance in soccer. J Hum Kinet. 2012;35:89-95. https://doi.org/10.2478/v10078-012-0082-9.

8. Carling C, Gregson W, McCall A, Moreira A, del Wong P, Bradley PS. Match running performance during fixture congestion in elite soccer: research issues and future directions. Sports Med. 2015;45(5):605-13. https://doi.org/10.1007/s40279-015-0313-z.

9. Reilly T, Drust B, Clarke N. Muscle fatigue during football match-play. Sports Med. 2008;38(5):357-67.

10. Sarmento H, Clemente FM, Araújo D, Davids K, McRobert A, Figueiredo A. What performance analysts need to know about research trends in Association Football (2012-2016): a systematic review. Sports Med. 2018;48(4):799-836. https://doi. org/10.1007/s40279-017-0836-6.

11. Taylor JB, Wright AA, Dischiavi SL, Townsend MA, Marmon AR. Activity demands during multi-directional team sports: a systematic review. Sports Med. 2017;47(12):2533-51. https:// doi.org/10.1007/s40279-017-0772-5.

12. Buchheit M, Mendez-villanueva A, Simpson BM, Bourdon PC. Repeated-sprint sequences during youth soccer matches. Int J Sports Med. 2010;31(10):709-16. https://doi. org/10.1055/s-0030-1261897.

13. Harley JA, Barnes CA, Portas M, Lovell R, Barrett S, Paul D, et al. Motion analysis of match-play in elite U12 to U16 agegroup soccer players. J Sports Sci. 2010;28(13):1391-7. https:// doi.org/10.1080/02640414.2010.510142.

14. Mendez-Villanueva A, Buchheit M, Simpson B, Bourdon PC. Match play intensity distribution in youth soccer. Int J Sports Med. 2013;34(2):101-10. https://doi.org/10.1055/s-0032-13063 23.

15. Goto H, Morris JG, Nevill ME. Motion analysis of U11 to U16 elite English Premier League Academy players. J Sports Sci. 2015;33(12):1248-58. https://doi.org/10.1080/02640 414.2014.999700.

16. Atan SA, Foskett A, Ali A. Motion analysis of match play in New Zealand U13 to U15 age-group soccer players. J Strength Cond Res. 2016;30(9):2416-23. https://doi.org/10.1519/JSC.00000 00000001336.

17. Al Haddad H, Simpson BM, Buchheit M, Di Salvo V, MendezVillanueva A. Peak match speed and maximal sprinting speed in young soccer players: effect of age and playing position.
Int J Sports Physiol Perform. 2015;10(7):888-96. https://doi. org/10.1123/ijspp.2014-0539.

18. Buchheit M, Mendez-Villanueva A, Simpson BM, Bourdon PC. Match running performance and fitness in youth soccer. Int J Sports Med. 2010;31(11):818-25. https://doi. org/10.1055/s-0030-1262838.

19. Saward C, Morris JG, Nevill ME, Nevill AM, Sunderland C. Longitudinal development of match-running performance in elite male youth soccer players. Scand J Med Sci Sports. 2016;26(8):933-42. https://doi.org/10.1111/sms.12534.

20. Bellistri G, Marzorati M, Sodero L, Sforza C, Bradley PS, Porcelli S. Match running performance and physical capacity profiles of U8 and U10 soccer players. Sport Sci Health. 2017;13(2):273-80. https://doi.org/10.1007/s11332-016-0328-3.

21. Barros RM, Misuta MS, Menezes RP, Figueroa PJ, Moura FA, Cunha SA, et al. Analysis of the distances covered by first division brazilian soccer players obtained with an automatic tracking method. J Sports Sci Med. 2007;6(2):233-42.

22. Vieira LHP, Milioni F, Barbieri RA, Rodrigues CM, Calsani EP, Tourinho Filho H, et al. Rastreamento de jogadores de futsal: uma revisão de literatura. Rev Min Educ Fis. 2016;24(1):70-107.

23. Andrzejewski M, Pluta B, Posiadala D. Characteristics of physical loads of young footballers during a championship match. J Hum Kinet. 2009;21:83-8. https://doi.org/10.2478/v1007 8-09-0010-9.

24. Castagna C, D'Ottavio S, Abt G. Activity profile of young soccer players during actual match play. J Strength Cond Res. 2003;17(4):775-80.

25. Aquino R, Munhoz Martins GH, Palucci Vieira LH, Menezes RP. Influence of match location, quality of opponents, and match status on movement patterns in Brazilian professional football players. J Strength Cond Res. 2017;31(8):2155-61. https://doi. org/10.1519/JSC.0000000000001674.

26. Goto H, Morris JG, Nevill ME. Match analysis of U9 and U10 English premier league academy soccer players using a global positioning system: relevance for talent identification and development. J Strength Cond Res. 2015;29(4):954-63. https://doi. org/10.1519/JSC.0b013e3182a0d751.

27. Pereira Da Silva N, Kirkendall DT, De Barros Leite, Neto T. Movement patterns in elite Brazilian youth soccer. J Sports Med Phys Fit. 2007;47(3):270-5.

28. Aquino R, Palucci LHV, de Oliveira Paula L, Cruz Goncalves LG, Pereira Santiago PR. Relationship between field tests and match running performance in high-level young Brazilian soccer players. J Sports Med Phys Fit. 2018;58(3):256-62. https://doi. org/10.23736/S0022-4707.17.06651-8.

29. Aslan A, Acikada C, Guvenc A, Goren H, Hazir T, Ozkara A Metabolic demands of match performance in young soccer players. J Sports Sci Med. 2012;11(1):170-9.

30. Aughey RJ, Hammond K, Varley MC, Schmidt WF, Bourdon PC, Buchheit M, et al. Soccer activity profile of altitude versus sealevel natives during acclimatisation to $3600 \mathrm{~m}$ (ISA3600). Br J Sports Med. 2013;47(Suppl 1):i107-13. https://doi.org/10.1136/ bjsports-2013-092776.

31. Pettersen SA, Krustrup P, Bendiksen M, Randers MB, Brito J, Bangsbo J, et al. Caffeine supplementation does not affect match activities and fatigue resistance during match play in young football players. J Sports Sci. 2014;32(20):1958-65. https://doi. org/10.1080/02640414.2014.965189.

32. Aquino RLQT, Cruz Goncalves LG, Palucci Vieira LH, Oliveira LP, Alves GF, Pereira Santiago PR, et al. Periodization training focused on technical-tactical ability in young soccer players positively affects biochemical markers and game performance. J Strength Cond Res. 2016;30(10):2723-32. https://doi. org/10.1519/JSC.0000000000001381. 
33. Waldron M, Murphy A. A comparison of physical abilities and match performance characteristics among elite and subelite under-14 soccer players. Pediatr Exerc Sci. 2013;25(3):423-34. https://doi.org/10.1123/pes.25.3.423.

34. Moher D, Liberati A, Tetzlaff J, Altman DG. Preferred reporting items for systematic reviews and meta-analyses: the PRISMA statement. PLoS Med. 2009;6(7):e1000097. https://doi. org/10.1371/journal.pmed.1000097.

35. Bishop C, Turner A, Read P. Effects of inter-limb asymmetries on physical and sports performance: a systematic review. J Sports Sci. 2018;36(10):1135-44. https://doi.org/10.1080/02640 414.2017.1361894.

36. Castellano J, Alvarez-Pastor D, Bradley PS. Evaluation of research using computerised tracking systems (Amisco and Prozone) to analyse physical performance in elite soccer: a systematic review. Sports Med. 2014;44(5):701-12. https://doi. org/10.1007/s40279-014-0144-3.

37. Capranica L, Tessitore A, Guidetti L, Figura F. Heart rate and match analysis in pre-pubescent soccer players. J Sports Sci. 2001;19(6):379-84. https://doi.org/10.1080/026404101300149 339.

38. Stroyer J, Hansen L, Klausen K. Physiological profile and activity pattern of young soccer players during match play. Med Sci Sports Exerc. 2004;36(1):168-74. https://doi.org/10.1249/01. MSS.0000106187.05259.96.

39. Castagna C, Impellizzeri F, Cecchini E, Rampinini E, Alvarez JC. Effects of intermittent-endurance fitness on match performance in young male soccer players. J Strength Cond Res. 2009;23(7):1954-9. https://doi.org/10.1519/JSC.0b013e3181 b7f743.

40. Castagna C, Manzi V, Impellizzeri F, Weston M, Barbero Alvarez JC. Relationship between endurance field tests and match performance in young soccer players. J Strength Cond Res. 2010;24(12):3227-33. https://doi.org/10.1519/JSC.0b013e3181 e72709.

41. Mendez-Villanueva A, Buchheit M, Simpson B, Peltola E, Bourdon $P$. Does on-field sprinting performance in young soccer players depend on how fast they can run or how fast they do run? J Strength Cond Res. 2011;25(9):2634-8. https://doi.org/10.1519/ JSC.0b013e318201c281.

42. Buchheit M, Simpson BM, Mendez-Villanueva A. Repeated high-speed activities during youth soccer games in relation to changes in maximal sprinting and aerobic speeds. Int J Sports Med. 2013;34(1):40-8. https://doi.org/10.1055/s-0032-1316363.

43. Rebelo A, Brito J, Seabra A, Oliveira J, Krustrup P. Physical match performance of youth football players in relation to physical capacity. Eur J Sport Sci. 2014;14(Suppl 1):S148-56. https:// doi.org/10.1080/17461391.2012.664171.

44. Hunter F, Bray J, Towlson C, Smith M, Barrett S, Madden J, et al. Individualisation of time-motion analysis: a method comparison and case report series. Int J Sports Med. 2015;36(1):41-8. https ://doi.org/10.1055/s-0034-1384547.

45. Aquino RL, Goncalves LG, Vieira LH, Oliveira LP, Alves GF, Santiago PR, et al. Biochemical, physical and tactical analysis of a simulated game in young soccer players. J Sports Med Phys Fit. 2016;56(12):1554-61.

46. Fernandes-da-Silva J, Castagna C, Teixeira AS, Carminatti LJ, Guglielmo LG. The peak velocity derived from the Carminatti Test is related to physical match performance in young soccer players. J Sports Sci. 2016;34(24):2238-45. https://doi. org/10.1080/02640414.2016.1209307.

47. Doncaster G, Marwood S, Iga J, Unnithan V. Influence of oxygen uptake kinetics on physical performance in youth soccer. Eur J Appl Physiol. 2016;116(9):1781-94. https://doi.org/10.1007/ s00421-016-3431-x.
48. Varley MC, Gregson W, McMillan K, Bonnano D, Stafford K, Modonutti M, et al. Physical and technical performance of elite youth soccer players during international tournaments: influence of playing position and team success and opponent quality. Sci Med Footb. 2017;1(1):18-29.

49. Arruda AF, Carling C, Zanetti V, Aoki MS, Coutts AJ, Moreira A. Effects of a very congested match schedule on body-load impacts, accelerations, and running measures in youth soccer players. Int J Sports Physiol Perform. 2015;10(2):248-52. https ://doi.org/10.1123/ijspp.2014-0148.

50. Sporis G, Dujic I, Trajkovic N, Milanovic Z, Madic D. Relationship between morphological characteristics and match performance in junior soccer players. Int J Morphol. 2017;35(1):37-41. https://doi.org/10.4067/S0717-95022017000100007.

51. Buchheit M, Horobeanu C, Mendez-Villanueva A, Simpson BM, Bourdon PC. Effects of age and spa treatment on match running performance over two consecutive games in highly trained young soccer players. J Sports Sci. 2011;29(6):591-8. https://doi. org/10.1080/02640414.2010.546424.

52. Rowsell GJ, Coutts AJ, Reaburn P, Hill-Haas S. Effect of postmatch cold-water immersion on subsequent match running performance in junior soccer players during tournament play. J Sports Sci. 2011;29(1):1-6. https://doi.org/10.1080/02640 414.2010.512640.

53. Garvican LA, Hammond K, Varley MC, Gore CJ, Billaut F, Aughey RJ. Lower running performance and exacerbated fatigue in soccer played at $1600 \mathrm{~m}$. Int J Sports Physiol Perform. 2014;9(3):397-404. https://doi.org/10.1123/ijspp.2012-0375.

54. Randers MB, Andersen TB, Rasmussen LS, Larsen MN, Krustrup P. Effect of game format on heart rate, activity profile, and player involvement in elite and recreational youth players. Scand J Med Sci Sports. 2014;24(Suppl 1):17-26. https://doi. org/10.1111/sms.12255.

55. Andrzejewski M, Chmura J, Wiacek M, Zubrzycki IZ. Influence of individualized training on psychomotor performance of young soccer players. J Strength Cond Res. 2011;25(2):374-8. https:// doi.org/10.1519/JSC.0b013e3181bac390.

56. Randers MB, Mujika I, Hewitt A, Santisteban J, Bischoff R, Solano R, et al. Application of four different football match analysis systems: a comparative study. J Sports Sci. 2010;28(2):17182. https://doi.org/10.1080/02640410903428525.

57. Romagnoli M, Sanchis-Gomar F, Alis R, Risso-Ballester J, Bosio A, Graziani RL, et al. Changes in muscle damage, inflammation, and fatigue-related parameters in young elite soccer players after a match. J Sports Med Phys Fit. 2016;56(10):1198-205.

58. Buchheit M, Hammond K, Bourdon PC, Simpson BM, Garvican-Lewis LA, Schmidt WF, et al. Relative match intensities at high altitude in highly-trained young soccer players (ISA3600). J Sports Sci Med. 2015;14(1):98-102.

59. Helgerud J, Engen LC, Wisloff U, Hoff J. Aerobic endurance training improves soccer performance. Med Sci Sports Exerc. 2001;33(11):1925-31.

60. Buchheit M, Mendez-Villanueva A. Effects of age, maturity and body dimensions on match running performance in highly trained under-15 soccer players. J Sports Sci. 2014;32(13):1271-8. https ://doi.org/10.1080/02640414.2014.884721.

61. Bravo-Sánchez A, Abián-Vicén J, Abián P. Analysis of the physical and technical differences between 7-a-side and 8-a-side game modalities in official under 12 soccer matches. Int J Perform Anal Sport. 2017;17(4):545-54. https://doi.org/10.1080/24748 668.2017.1366760.

62. Brito Â, Roriz P, Silva P, Duarte R, Garganta J. Effects of pitch surface and playing position on external load activity profiles and technical demands of young soccer players in match play. 
Int J Perform Anal Sport. 2017;17(6):902-18. https://doi. org/10.1080/24748668.2017.1407207.

63. Dello Iacono A, Martone D, Cular D, Milic M, Padulo J. Game profile-based training in soccer: a new field approach. J Strength Cond Res. 2017;31(12):3333-42. https://doi.org/10.1519/JSC00 00000000001768.

64. Kęsicki G, Lewicki W. Innovative dimension of using telematics tools in training processes of young football players. Trends Sport Sci. 2017;24(4):167-73. https://doi.org/10.23829/ TSS.2017.24-4.

65. Rago V, Pizzuto F, Raiola G. Relationship between intermittent endurance capacity and match performance according to the playing position in sub-19 professional male football players: preliminary results. J Phys Educ Sport. 2017;17(2):688-91. https ://doi.org/10.7752/jpes.2017.02103.

66. Izzo R, Varde'i CH. Differences by field positions between young and senior amateur soccer players using GPS technologies. Ovidius Univ Ann Ser Phys Educ Sport Sci Mov Health. 2017;17(2):344-52.

67. Vigh-Larsen JF, Dalgas U, Andersen TB. Position-specific acceleration and deceleration profiles in elite youth and senior soccer players. J Strength Cond Res. 2018;32(4):1114-22. https://doi. org/10.1519/JSC0000000000001918.

68. Bangsbo J, Iaia FM, Krustrup P. The Yo-Yo intermittent recovery test : a useful tool for evaluation of physical performance in intermittent sports. Sports Med. 2008;38(1):37-51.

69. Zacharogiannis E, Paradisis G, Tziortzis S. An evaluation of tests of anaerobic power and capacity. Med Sci Sports Exerc. 2004;36(5):S116. https://doi.org/10.1249/00005768-20040500100549.

70. Hoff J, Wisløff U, Engen LC, Kemi OJ, Helgerud J. Soccer specific aerobic endurance training. Br J Sports Med. 2002;36(3):218-21. https://doi.org/10.1136/bjsm.36.3.218.

71. Mendez-Villanueva A, Buchheit M, Kuitunen S, Poon TK, Simpson B, Peltola E. Is the relationship between sprinting and maximal aerobic speeds in young soccer players affected by maturation? Pediatr Exerc Sci. 2010;22(4):497-510. https://doi. org/10.1123/pes.22.4.497.

72. Ohashi J, Miyagi O, Nagahama H, Ogushi T, Ohashi K. Application of an analysis system evaluating intermittent activity during a soccer match. In: Spinks W, Reilly T, Murphy A, editors. Science and football IV. London: Routledge; 2002.

73. Carling C, Collins D. Comment on "Match analysis of U9 and U10 English premier league academy soccer players using a global positioning system: relevance for talent identification and development". J Strength Cond Res. 2017;31(2):e61-3. https:// doi.org/10.1519/JSC.0000000000000466.

74. English Premier League. Games Programme. EPL. 2012. https ://www.premierleague.com/youth/games-programme. Accessed 07 Dec 2017.

75. Auckland Football Federation. 2017 Federation Competition Regulations, AFF youth 9th to 17th grades: general provisions. AFF. 2017. http://www.aucklandfootball.org.nz/comps/regul ations-resources. Accessed 07 Dec 2017.

76. Federazione Italiana Giuoco Calcio. Attività di base. FIGC. 2017. http://www.figc.it/en/3332/21180/Attivita_SGS.shtml. Accessed 07 Dec 2017.

77. Malina RM, Eisenmann JC, Cumming SP, Ribeiro B, Aroso J. Maturity-associated variation in the growth and functional capacities of youth football (soccer) players 13-15 years. Eur J Appl Physiol. 2004;91(5-6):555-62. https://doi.org/10.1007/ s00421-003-0995-z.

78. Goto H, Morris JG, Nevill ME. Influence of biological maturity on the match performance of 8-16 year old elite male youth soccer players. J Strength Cond Res. 2018. https://doi. org/10.1519/jsc.0000000000002510 (Publish Ahead of Print).

79. Cumming SP, Brown DJ, Mitchell S, Bunce J, Hunt D, Hedges $\mathrm{C}$, et al. Premier League academy soccer players' experiences of competing in a tournament bio-banded for biological maturation. J Sports Sci. 2018;36(7):757-65. https://doi.org/10.1080/02640 414.2017.1340656.

80. Freitas CG, Aoki MS, Arruda AFS, Franciscon C, Moreira A. Monitoring salivary immunoglobulin a responses to official and simulated matches in elite young soccer players. J Hum Kinet. 2016;53:107-15. https://doi.org/10.1515/hukin-2016-0015.

81. Hill-Haas SV, Rowsell GJ, Dawson BT, Coutts AJ. Acute physiological responses and time-motion characteristics of two smallsided training regimes in youth soccer players. J Strength Cond Res. 2009;23(1):111-5. https://doi.org/10.1519/JSC.0b013e3181 efc1a.

82. Castellano J, Casamichana D, Dellal A. Influence of game format and number of players on heart rate responses and physical demands in small-sided soccer games. J Strength Cond Res. 2013;27(5):1295-303. https://doi.org/10.1519/JSC.0b013e3182 $67 \mathrm{a} 5 \mathrm{~d} 1$.

83. Massard T, Eggers T, Lovell R. Peak speed determination in football: is sprint testing necessary? Sci Med Footb. 2018;2(2):1236. https://doi.org/10.1080/24733938.2017.1398409.

84. Scott D, Lovell R. Individualisation of speed thresholds does not enhance the dose-response determination in football training. J Sports Sci. 2018;36(13):1523-32. https://doi.org/10.1080/02640 414.2017.1398894.

85. Buchheit M, Allen A, Poon TK, Modonutti M, Gregson W, Di Salvo V. Integrating different tracking systems in football: multiple camera semi-automatic system, local position measurement and GPS technologies. J Sports Sci. 2014;32(20):1844-57. https ://doi.org/10.1080/02640414.2014.942687.

86. Scott MT, Scott TJ, Kelly VG. The validity and reliability of global positioning systems in team sport: a brief review. $\mathrm{J}$ Strength Cond Res. 2016;30(5):1470-90. https://doi.org/10.1519/ JSC.0000000000001221.

87. Varley MC, Di Salvo V, Modonutti M, Gregson W, MendezVillanueva A. The influence of successive matches on matchrunning performance during an under-23 international soccer tournament: The necessity of individual analysis. J Sports Sci. 2018;36(5):585-91. https://doi.org/10.1080/02640 414.2017.1325511.

88. Valter DS, Adam C, Barry M, Marco C. Validation of Prozone ${ }^{\circledR}$ : a new video-based performance analysis system. Int J Perform Anal Sport. 2006;6(1):108-19. https://doi.org/10.1080/24748 668.2006 .11868359$.

89. Barris S, Button C. A review of vision-based motion analysis in sport. Sports Med. 2008;38(12):1025-43. https://doi. org/10.2165/00007256-200838120-00006.

90. Figueroa PJ, Leite NJ, Barros RML. Background recovering in outdoor image sequences: an example of soccer players segmentation. Image Vis Comput. 2006;24(4):363-74. https://doi. org/10.1016/j.imavis.2005.12.012.

91. Palucci Vieira LH, Aquino R, Lago-Peñas C, Munhoz Martins GH, Puggina EF, Barbieri FA. Running performance in Brazilian professional football players during a congested match schedule. J Strength Cond Res. 2018;32(2):313-25. https://doi. org/10.1519/JSC.0000000000002342.

92. Paul DJ, Bradley PS, Nassis GP. Factors affecting match running performance of elite soccer players: shedding some light on the complexity. Int J Sports Physiol Perform. 2015;10(4):516-9. https://doi.org/10.1123/IJSPP.2015-0029.

93. Carling C. Interpreting physical performance in professional soccer match-play: should we be more pragmatic in our approach? 
Sports Med. 2013;43(8):655-63. https://doi.org/10.1007/s4027 9-013-0055-8.

94. Bradley PS, Ade JD. Are current physical match performance metrics in elite soccer fit for purpose or is the adoption of an integrated approach needed? Int J Sports Physiol Perform. 2018;13(5):656-64. https://doi.org/10.1123/ijspp.2017-0433.

95. Lago-Peñas C, Rey E, Lago-Ballesteros J. The influence of effective playing time on physical demands of elite soccer players. Open Sports Sci J. 2012;5:188-92. https://doi.org/10.2174/18753 99X01205010188.

96. Mendez-Villanueva A, Buchheit M. Football-specific fitness testing: adding value or confirming the evidence? J Sports Sci. 2013;31(13):1503-8. https://doi.org/10.1080/02640 414.2013.823231.

97. Nassis GP, Brito J, Dvorak J, Chalabi H, Racinais S. The association of environmental heat stress with performance: analysis of the 2014 FIFA World Cup Brazil. Br J Sports Med. 2015;49:60913. https://doi.org/10.1136/bjsports-2014-094449.

98. Falk B, Dotan R. Temperature regulation and elite young athletes. Med Sport Sci. 2011;56:126-49. https://doi.org/10.1159/00032 0645.

99. Lago-Penas C, Rey E, Lago-Ballesteros J, Casais L, Dominguez E. The influence of a congested calendar on physical performance in elite soccer. J Strength Cond Res. 2011;25(8):2111-7. https://doi.org/10.1519/JSC0b013e3181eccdd2.

100. Dellal A, Lago-Penas C, Rey E, Chamari K, Orhant E. The effects of a congested fixture period on physical performance, technical activity and injury rate during matches in a professional soccer team. Br J Sports Med. 2015;49(6):390-4. https:// doi.org/10.1136/bjsports-2012-091290.

101. Folgado H, Duarte R, Marques P, Sampaio J. The effects of congested fixtures period on tactical and physical performance in elite football. J Sports Sci. 2015;33(12):1238-47. https://doi. org/10.1080/02640414.2015.1022576.

102. Buchheit M, Mendez-Villanueva A. Reliability and stability of anthropometric and performance measures in highly-trained young soccer players: effect of age and maturation. J Sports Sci. 2013;31(12):1332-43. https://doi.org/10.1080/02640 414.2013.781662.
103. Castellano J, Blanco-Villasenor A, Alvarez D. Contextual variables and time-motion analysis in soccer. Int J Sports Med. 2011;32(6):415-21. https://doi.org/10.1055/s-0031-1271771.

104. Carling C, Wright C, Nelson LJ, Bradley PS. Comment on "Performance analysis in football: a critical review and implications for future research". J Sports Sci. 2014;32(1):2-7. https://doi. org/10.1080/02640414.2013.807352.

105. Requena B, de Villarreal ESS, Gapeyeva H, Ereline J, Garcia I, Paasuke M. Relationship between postactivation potentiation of knee extensor muscles, sprinting and vertical jumping performance in professional soccer players. J Strength Cond Res. 2011;25(2):367-73. https://doi.org/10.1519/JSC.0b013e3181 be31aa.

106. Bellinger PM. $\beta$-Alanine supplementation for athletic performance: an update. J Strength Cond Res. 2014;28(6):1751-70. https://doi.org/10.1519/JSC.0000000000000327.

107. Nedelec M, McCall A, Carling C, Legall F, Berthoin S, Dupont G. Recovery in soccer: part II-recovery strategies. Sports Med. 2013;43(1):9-22. https://doi.org/10.1007/s40279-012-0002-0.

108. Sainani KL. The problem with "magnitude-based inference". Med Sci Sports Exerc. 2018;50(10):2166-76. https://doi. org/10.1249/MSS.0000000000001645.

109. Hopkins WG, Marshall SW, Batterham AM, Hanin J. Progressive statistics for studies in sports medicine and exercise science. Med Sci Sports Exerc. 2009;41(1):3-13. https://doi.org/10.1249/ MSS.0b013e31818cb278.

110. Knudson D. Confidence crisis of results in biomechanics research. Sports Biomech. 2017;16(4):425-33. https://doi. org/10.1080/14763141.2016.1246603.

111. Hopkins WG, Batterham AM. Error rates, decisive outcomes and publication bias with several inferential methods. Sports Med. 2016;46(10):1563-73. https://doi.org/10.1007/s4027 9-016-0517-x.

112. Buchheit M. The numbers will love you back in return-I promise. Int J Sports Physiol Perform. 2016;11(4):551-4. https://doi. org/10.1123/IJSPP.2016-0214.

\section{Affiliations}

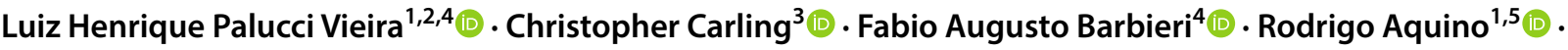 Paulo Roberto Pereira Santiago ${ }^{1,2}(\mathbb{0})$}

Paulo Roberto Pereira Santiago

paulosantiago@usp.br

1 FMRP Faculty of Medicine at Ribeirão Preto, University of São Paulo, Avenue Bandeirantes 3900-Monte Alegre, Ribeirão Preto, São Paulo 14049-900, Brazil

2 LaBioCoM Biomechanics and Motor Control Laboratory, School of Physical Education and Sport of Ribeirão Preto, University of São Paulo, Campus Ribeirão Preto, Ribeirão Preto, SP, Brazil
3 Institute of Coaching and Performance, University of Central Lancashire, Preston, UK

4 MOVI-LAB Human Movement Research Laboratory, Physical Education Department, Faculty of Sciences, São Paulo State University UNESP, Campus Bauru, Bauru, SP, Brazil

5 CIFI2D, FADEUP Faculty of Sports, University of Porto, Porto, Portugal 